ARTICLE

\title{
Protective mucosal immunity against SARS-CoV-2 after heterologous systemic prime-mucosal boost immunization
}

Dennis Lapuente (1) ${ }^{1 凶}$, Jana Fuchs ${ }^{1}$, Jonas Willar ${ }^{1}$, Ana Vieira Antão ${ }^{1}$, Valentina Eberlein ${ }^{2,3}$, Nadja Uhlig (iD ${ }^{2,3}$, Leila Issmail ${ }^{2,3}$, Anna Schmidt ${ }^{1}$, Friederike Oltmanns ${ }^{1}$, Antonia Sophia Peter ${ }^{1}$, Sandra Mueller-Schmucker ${ }^{1}$, Pascal Irrgangㄱ, Kirsten Fraedrich¹, Andrea Cara (1) 4, Markus Hoffmann (1) 5,6, Stefan Pöhlmann (1) 5,6, Armin Ensser ${ }^{1}$, Cordula Pertl ${ }^{7}$, Torsten Willert ${ }^{7}$, Christian Thirion7 ${ }^{7}$, Thomas Grunwald ${ }^{2,3}$, Klaus Überla ${ }^{1} \&$ Matthias Tenbusch (1D ${ }^{1 凶}$

Several effective SARS-CoV-2 vaccines are currently in use, but effective boosters are needed to maintain or increase immunity due to waning responses and the emergence of novel variants. Here we report that intranasal vaccinations with adenovirus 5 and 19a vectored vaccines following a systemic plasmid DNA or mRNA priming result in systemic and mucosal immunity in mice. In contrast to two intramuscular applications of an mRNA vaccine, intranasal boosts with adenoviral vectors induce high levels of mucosal $\lg A$ and lung-resident memory $T$ cells $\left(T_{R M}\right)$; mucosal neutralization of virus variants of concern is also enhanced. The mRNA prime provokes a comprehensive $T$ cell response consisting of circulating and lung $T_{R M}$ after the boost, while the plasmid DNA prime induces mostly mucosal $T$ cells. Concomitantly, the intranasal boost strategies lead to complete protection against a SARSCoV-2 infection in mice. Our data thus suggest that mucosal booster immunizations after mRNA priming is a promising approach to establish mucosal immunity in addition to systemic responses.

\footnotetext{
${ }^{1}$ Institute of Clinical and Molecular Virology, University Hospital Erlangen, Friedrich-Alexander University Erlangen-Nürnberg, Erlangen, Germany. ${ }^{2}$ Department of Immunology, Fraunhofer Institute for Cell Therapy and Immunology, IZI, Leipzig, Germany. ${ }^{3}$ Fraunhofer Cluster of Excellence Immunemediated Diseases CIMD, Frankfurt am Main, Germany. ${ }^{4}$ National Center for Global Health, Istituto Superiore di Sanità, Rome, Italy. ${ }^{5}$ Infection Biology Unit, German Primate Center-Leibniz Institute for Primate Research, Göttingen, Germany. ${ }^{6}$ Faculty of Biology and Psychology, Georg-August-University Göttingen, Göttingen, Germany. ${ }^{7}$ Sirion Biotech, Martinsried, Germany. ${ }^{凶}$ email: Dennis.Lapuente@uk-erlangen.de; matthias.tenbusch@fau.de
} 
T he severe acute respiratory syndrome coronavirus 2 (SARS-CoV-2) emerged in late 2019 and caused a worldwide pandemic accounting for over 190 million infections and 4 million deaths at the time of this report ${ }^{1}$. In an unprecedented speed, academic institutions and biotech companies developed, evaluated, and licensed several SARS-CoV-2 vaccines. Beside traditional approaches like protein subunit or inactivated virus vaccines, gene-based vaccines were at the forefront of the developmental process and the first to become licensed ${ }^{2}$.

Vaccines based on messenger RNA (mRNA) or adenoviral vectors (Ad) demonstrated efficacy against SARS-CoV-2 infections and, most importantly, against severe coronavirus disease 2019 (COVID-19) and death ${ }^{3-6}$. Humoral as well as cellular immune responses against the spike (S) surface protein were successfully induced by both types of vaccines ${ }^{7-11}$. However, breakthrough infections of fully vaccinated individuals have been reported and the numbers might increase in the phase of waning immunity ${ }^{12-18}$. The impact of immune escape and newly emerging virus variants (i.e. variants of concern, VOCs) is controversially discussed in some of these studies. Upon breakthrough infections, virus replication in the respiratory tract is approximately four- to six-fold reduced compared to unvaccinated and virus shedding seems to be shorter in duration ${ }^{14,19}$. Importantly, Public Health England reported that after the first dose of an mRNA (Comirnaty ${ }^{\circledR}$ ) or viral vector vaccine (Vaxzevria $^{\circ}$ ) the likelihood of household transmission drops by $40-50 \%^{20}$. On one hand, these observations underline that the current vaccination campaigns can end the pandemic phase by reducing the basic reproduction number below 1 . On the other hand, however, it also demonstrates that transmission is still possible by vaccinated individuals posing a risk to vulnerable communities.

While the currently approved vaccines induce systemic immune responses, they probably do not evoke mucosal immunity in form of mucosal, secretory immunoglobulin A $(\operatorname{IgA})$ or tissue-resident memory $T$ cells $\left(T_{R M}\right)$. Secretory, polymeric $\operatorname{IgA}$ can neutralize incoming viral particles at the mucosal surface before infection of epithelial cells takes place, which is important for an optimal protection against respiratory virus infections $s^{21-23}$. Furthermore, IgA enables specific effector functions by crosslinking the Fca-receptor, and polymeric forms of IgA might increase antibody avidity ${ }^{24}$. So far, the only licenced intranasal vaccines are live-attenuated influenza vaccines (LAIV). Nasal IgA contributes to the efficacy of these vaccines in children ${ }^{25}$ and also correlates with protection in experimental human challenge studies ${ }^{26}$. Importantly, local antigen deposition by mucosal vaccination routes is key for an induction of mucosal IgA as shown in humans ${ }^{24,27-29}$ and animal models ${ }^{30-32}$. While IgA can be effectively induced by intranasal delivery of protein-based vaccines, an efficient induction of respiratory $\mathrm{CD} 8^{+} \mathrm{T}_{\mathrm{RM}}$ usually requires local antigen production in the mucosa followed by major histocompatibility complex-I-mediated peptidepresentation by stromal and, most importantly, by migratory $\mathrm{CD}_{103^{+}}$dendritic cells ${ }^{33}$. CD8 ${ }^{+} \mathrm{T}_{\mathrm{RM}}$ localize within the respiratory epithelium or the airways and can respond immediately in case of secondary infections. In contrast to circulatory $\mathrm{T}$ cell memory phenotypes like central memory $\left(\mathrm{T}_{\mathrm{CM}}\right)$, effectormemory $\left(\mathrm{T}_{\mathrm{EM}}\right.$ ), or effector $\mathrm{T}$ cells $\left(\mathrm{T}_{\mathrm{EFF}}\right), \mathrm{T}_{\mathrm{RM}}$ do not significantly recirculate ${ }^{34,35}$. Thus, one feature of $T_{R M}$ is the direct localization at barrier tissues, which makes a time-consuming migration into the inflamed lung redundant. A second remarkable characteristic is the ability to exert innate and adaptive functions within a few hours after secondary infection ${ }^{36,37}$, in part due to the storage of ready-made mRNAs encoding cytokines like IFN $\gamma$ at steady state $^{38,39}$. Altogether, these unique features of mucosal immune responses enable an immediate and effective countermeasure against pulmonary infections as described for flu ${ }^{40,41}$, respiratory syncytial virus (RSV) ${ }^{42}$, and Mycobacterium tuberculosis ${ }^{43,44}$. The great majority of these findings were generated in animal models, partly due to the invasive nature of bronchoalveolar lavages (BAL) and biopsy sampling. However, small experimental human challenge studies started to look precisely at the role of mucosal immunity against respiratory viruses ${ }^{45,46}$.

A few preclinical studies investigated intranasal SARS-CoV-2 vaccines so far. In a series of publications, one group reported protective efficacy of a one shot vaccination with an chimpanzee adenoviral vector (ChAd-SARS-CoV-2-S) vaccine encoding for the spike protein in mice, hamsters, and rhesus macaques ${ }^{47-49}$. Importantly, van Doremalen et al. have shown that intramuscular adenoviral vector (ChAdOx1) vaccination prevents pneumonia in macaques but allow for virus replication in the upper respiratory tract $^{50}$. However, administered intranasally, the vaccine attenuated nasal virus replication more efficiently ${ }^{51}$. It is important to investigate intranasal vaccine candidates not only as standalone modalities but also in the context of pre-existing immunity induced by a previous vaccination. On one hand, this is important due to the broad employment SARS-CoV-2 vaccines in recent vaccination campaigns. On the other hand, first clinical data point towards suboptimal immunogenicity of solely intranasal vaccinations against SARS-CoV-2 in humans without preexisting immunity, but also provides evidence for robust immunity after heterologous prime-boost vaccinations ${ }^{52,53}$.

In this study, mucosal vaccinations with adenoviral serotype 5 and 19a vectors are assessed in mice with or without prior systemic priming. We demonstrate that a systemic plasmid DNA or mRNA prime followed by an intranasal boost with an adenoviral serotype 5 vector (Ad5) enables a comprehensive systemic and local T cell immunity as well as substantial mucosal neutralization of SARS-CoV-2 VOCs. Concomitantly, the immunity established by mucosal boost strategies efficiently controls virus replication upon experimental infection comparable to homologous systemic immunizations. Considering mucosal boost immunization in individuals prior vaccinated with mRNA vaccines, may increase the efficacy of ongoing vaccination campaigns against SARSCoV-2. Furthermore, the concept might be also transferable for the future management of newly emerging respiratory tract viruses.

\section{Results}

A systemic plasmid DNA prime significantly increases the mucosal immunogenicity of an intranasal adenoviral vector vaccine. In this first part of our study, we evaluated the immunogenicity of mucosally applied viral vector vaccines as a single shot vaccine or as a booster after an intramuscular plasmid DNA prime immunization. To this end, codon-optimized sequences encoding the full-length $S$ and nucleocapsid $(\mathrm{N})$ proteins of SARS-CoV-2 were inserted into pVax-1 expression plasmids (in the following designated as plasmid DNA vaccine) and into replication-deficient adenoviral vector vaccines based on serotype 5 (Ad5) or serotype 19a (Ad19a). BALB/c mice were immunized intranasally with the Ad5- or Ad-19a-based vaccines either without prior treatment or four weeks after an intramuscular plasmid DNA immunization with S- and N-encoding plasmids (Fig. 1A). Two weeks later, SARS-CoV-2 specific antibody responses were analysed in serum and BAL samples, whereas the local and systemic $\mathrm{T}$ cell responses were determined in lungs and spleens, respectively.

In our flow cytometric assay ${ }^{54}$, spike-specific IgG, IgG1, and IgG2a could be easily detected in serum and BAL of animals treated with the prime-boost strategies, while antibodies in the BAL after a single dose of Ad19a or Ad5 were almost absent 
A

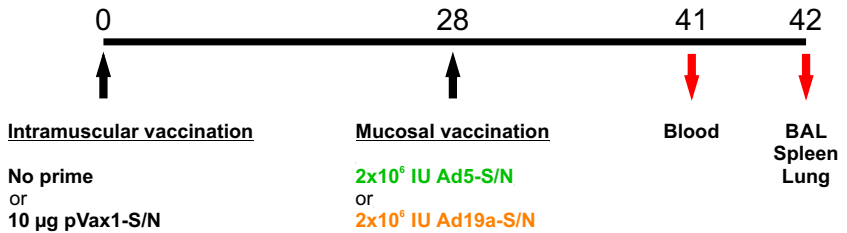

C

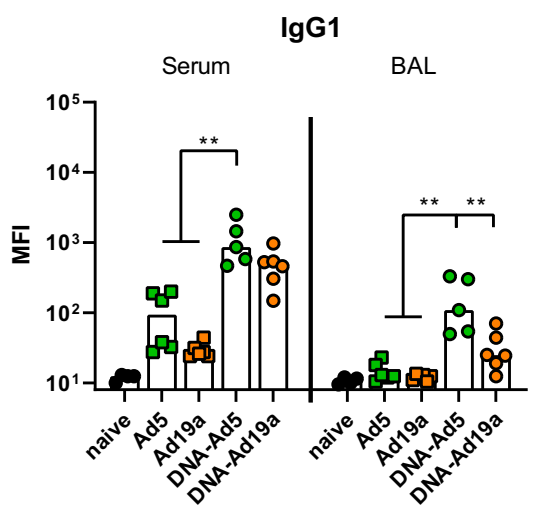

D

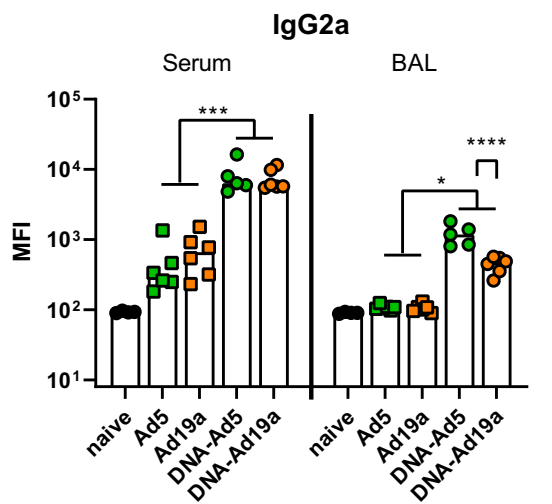

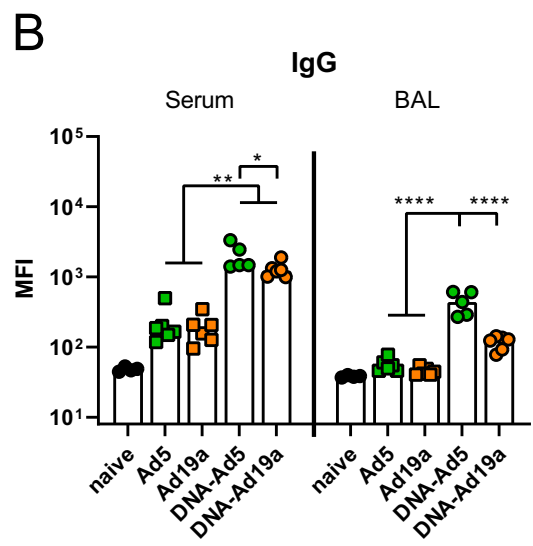

$E$

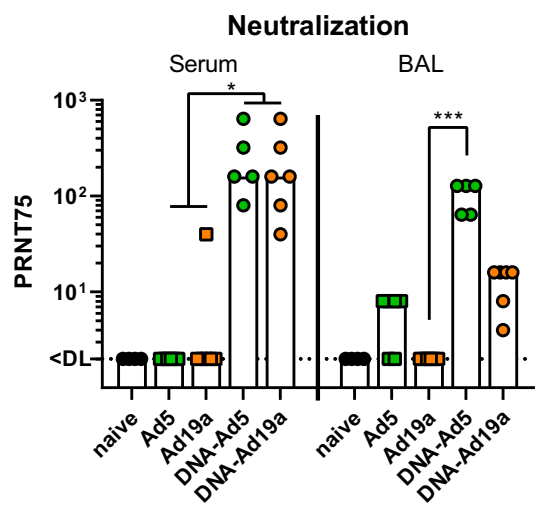

Fig. 1 Humoral responses after intranasal immunization with Ad5- or Ad19a-based viral vector vaccines. A BALB/c mice were immunized intranasally with Ad5- or Ad19a-based vectors encoding the $\mathrm{N}$ and S protein of SARS-CoV-2 ( $2 \times 10^{6}$ infectious units per vector). Mice from the heterologous primeboost groups were primed four weeks before by intramuscular injection of $\mathrm{N}$ - and $\mathrm{S}$-encoding DNA plasmids (10 $\mu \mathrm{g}$ per plasmid) followed by electroporation. Serum antibody responses were analysed thirteen days and mucosal immune responses in the BALs fourteen days after the mucosal immunization. Spike-specific $\lg$ (B), IgG1 (C), and IgG2a (D) were assessed by a flow cytometric approach (dilutions: sera 1:400, BAL 1:100). Plaque reduction neutralization titres (PRNT75) were determined by in vitro neutralization assays (E). Bars represent group medians overlaid with individual data points; naïve $n=4$; DNA-Ad5 $n=5$; other groups $n=6$. Data were analysed by one-way ANOVA followed by Tukey's post test (B-D) or by Kruskal-Wallis test (one-way ANOVA) followed by Dunn's multiple comparison test (E). Statistically significant differences are indicated only among the different vaccine groups; $p$ values indicate significant differences $\left({ }^{\star} p<0.05 ;{ }^{\star \star} p<0.005 ;{ }^{\star \star \star} p<0.0005 ;{ }^{\star \star \star \star} p<0.0001\right)$.

(Fig. 1B-D). Comparing the two adenoviral vectors as booster vaccines, the serotype 5 induced significantly higher levels of $\mathrm{S}$-specific antibodies in the BAL, although the antibody levels in the sera were comparable for the both groups. This effect was confirmed in the IgG subclass analyses for both, IgG1 and IgG2a levels (Fig. 1C, D). Similar trends were also observed for $\mathrm{N}$-specific antibody levels in sera and BALs (Supplementary Fig. 1). In line with the amount of S-binding antibodies, profound virus neutralization was detected in sera and BAL samples from the groups DNA-Ad5 and DNA-Ad19a, while Ad5 or Ad19a alone did not induce significant levels of neutralizing antibodies (Fig. 1E). Given the differences in the local antibody levels, the IgA response in the BAL towards specific domains of the $S$ protein were analysed in more detail by ELISA (Fig. 2A-C). These results confirmed that intranasal applications of Ad5-based vectors induce higher S-specific IgA levels than Ad19a-based vectors and these responses benefit from a systemic plasmid DNA prime. Furthermore, the vaccine-induced antibodies were directed against $\mathrm{S} 1$ including the receptor-binding domain (RBD) as well as against the $\mathrm{S} 2$ domain of the spike protein (Fig. 2A-C).

Next, we assessed the induction of cellular immune responses in the lung by the different vaccination schemes. Intravascular staining (iv-labelling) ${ }^{55}$ was used to differentiate between circulating $\mathrm{T}$ cells present in the lung endothelium during sampling (iv-) and $\mathrm{T}_{\mathrm{RM}}$ (iv+). Since specific MHC-I multimers were not available at the time of this study, antigen-experienced $\mathrm{T}$ cells were identified by the expression of CD44 (gating strategy shown in Supplementary Fig. 2). Similar to the humoral responses, $\mathrm{CD} 44^{+} \mathrm{CD} 8{ }^{+} \mathrm{T}$ cells in the lung were most efficiently induced by the DNA-Ad5 scheme, although all treated animals mounted vaccine-induced cellular responses (Fig. 3A). The vast majority of lung $\mathrm{CD}^{+} \mathrm{T}$ cells were protected from the ivlabelling in all groups, and the most prominent $\mathrm{T}_{\mathrm{RM}}$ phenotype was $\mathrm{CD}_{103}{ }^{+} \mathrm{CD} 9^{+}$(Fig. 3B). Antigen-specific $\mathrm{CD} 4^{+}$and $\mathrm{CD} 8{ }^{+}$ $\mathrm{T}$ cells were identified by ex vivo restimulation with peptide pools covering major parts of $\mathrm{S}$ and the complete $\mathrm{N}$ protein, respectively, followed by intracellular staining of accumulated cytokines (gating strategy in Supplementary Fig. 3). The highest percentages of S-reactive $\mathrm{CD}^{+} \mathrm{T}$ cells were detected in the lungs of DNA-Ad5 treated animals with the majority of them predominantly producing IFN $\gamma$ (Fig. 4A). Differences in the percentages of $\mathrm{CD}^{+} \mathrm{T}$ cells expressing IL-2 or TNF were less pronounced, and polyfunctional $\mathrm{T}$ cells positive for all four analytes including the degranulation marker CD107a were rarely found in all animals. In contrast, significantly elevated percentages of $\mathrm{CD}^{+} \mathrm{T}$ cells producing IFN $\gamma$ or TNF as well as 
A

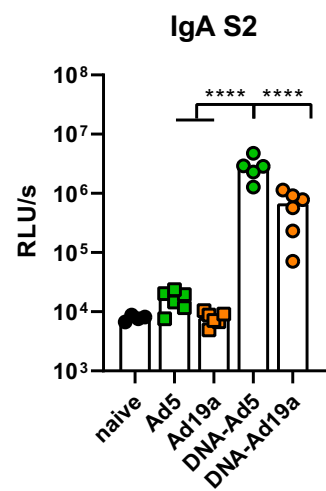

B

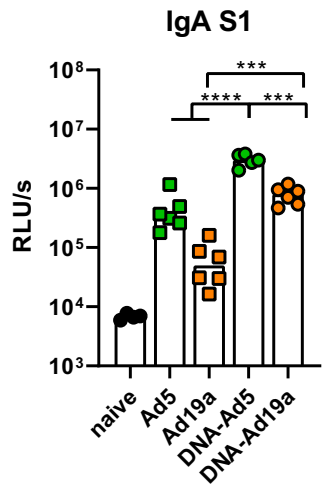

C

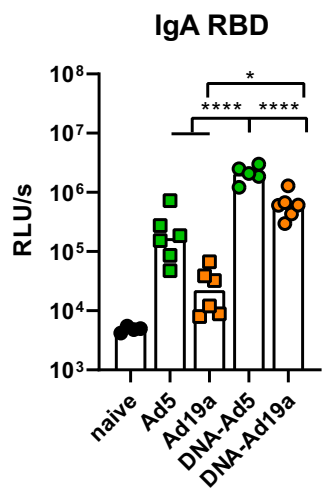

Fig. 2 Mucosal, spike-specific IgA responses. BALB/c mice were vaccinated according to Fig. 1A. BAL samples were tested for spike-specific lgA directed against the domains of S2 (A), S1 (B), or RBD $(\mathbf{C})$ by ELISA (dilution: 1:10). Bars represent group medians overlaid with individual data points; naïve $n=4$; DNA-Ad5 $n=5$; other groups $n=6$. Data were analysed by one-way ANOVA followed by Tukey's post test. Statistically significant differences are indicated only among the different vaccine groups; $p$ values indicate significant differences $\left({ }^{\star} p<0.05 ;{ }^{\star \star} p<0.005 ;{ }^{\star \star \star} p<0.0005 ;{ }^{\star \star \star \star} p<0.0001\right)$.
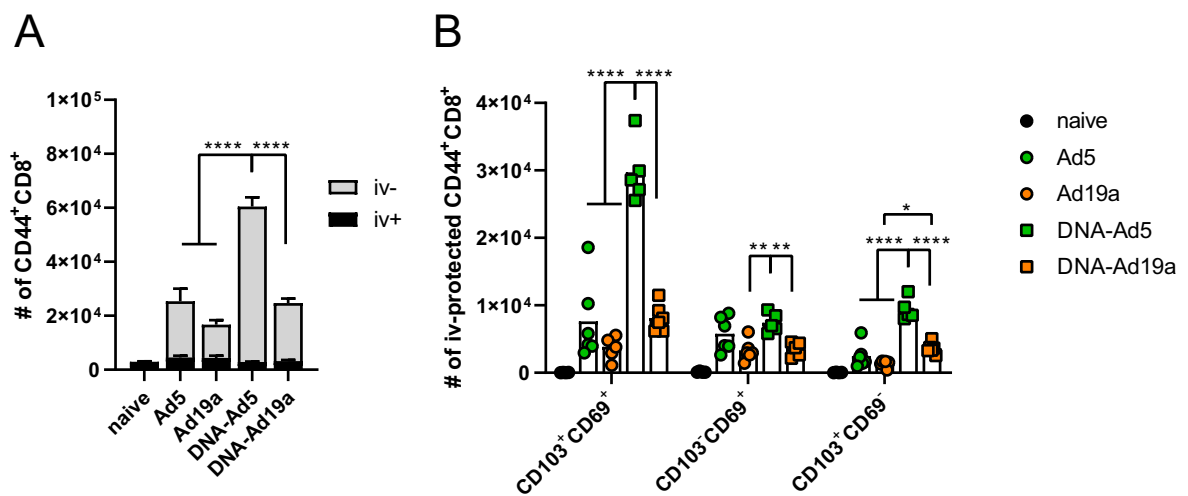

Fig. 3 Tissue-resident memory $\mathbf{T}$ cell subsets in the lung. BALB/c mice were vaccinated according to Fig. 1A. In absence of suitable MHC-I multimers, antigen-experienced $\mathrm{CD}^{+} \mathrm{T}$ cells were identified by CD44 staining (A). Intravascular staining was used to differentiate between circulating (iv + ) and tissue-resident (iv-) memory cells. Tissue-resident phenotypes were assessed by staining for CD69 and/or CD103 within the iv-protected memory compartment (B). The gating strategy is shown in Supplementary Fig. 2. Bars represent group means with SEM (A) or overlaid with individual data points (B); naïve $n=4$; DNA-Ad5 $n=5$; other groups $n=6$. Data were analysed by one-way ANOVA followed by Tukey's multiple comparison test. Statistical significant differences are indicated only among the different the vaccine groups; $p$ values indicate significant differences $\left({ }^{\star} p<0.05\right.$; ${ }^{\star \star} p<0.005$;

$\left.{ }^{\star \star \star} p<0.0005 ;{ }^{* \star \star \star} p<0.0001\right)$.

polyfunctional $\mathrm{CD}^{+} \mathrm{T}$ cells were detected in the spleens of DNA-Ad19a treated animals (Fig. 4C). Albeit at overall lower frequencies, the same observation was made for N-reactive CD8 ${ }^{+}$ $\mathrm{T}$ cells in lungs and spleens (Supplementary Fig. 4A, C). Pronounced S- and $\mathrm{N}$-specific $\mathrm{CD}^{+} \mathrm{T}$ cell responses were detected in all animals that received a prime-boost vaccination (Fig. 4 and Supplementary Fig. 4). In contrast to the CD8 ${ }^{+}$ $\mathrm{T}$ cells, the majority of the $\mathrm{CD} 4^{+} \mathrm{T}$ cells were polyfunctional indicated by the simultaneous expression of IFN $\gamma$, TNF and IL-2. Again, immunization with the Ad19a-based vectors resulted in higher systemic responses measured in the spleen, whereas the mucosal response in the lung was more pronounced after delivery of Ad5-based vectors (Fig. 4C, D, Supplementary Fig. 4C, D).

Taken together, Ad5 proved a higher immunogenicity as mucosal vaccine vector compared to Ad19a and resulted in strong cellular and humoral immune responses against SARS-CoV-2 antigens if combined with an intramuscular plasmid DNA prime immunization.

An intranasal boost following systemic mRNA vaccination potentiates mucosal antibody responses with pronounced neutralization breadth. Since mRNA vaccines are currently in use for mass vaccination campaigns in many countries, we wanted to compare the differential effects of a plasmid DNA or mRNA prime on the immunogenicity of a mucosal booster. Therefore, the previously described DNA-Ad5 scheme was compared to an mRNA prime (Comirnaty ${ }^{\circledast}$, Biontech/Pfizer) followed by an intranasal Ad5 boost (RNA-Ad5). Moreover, two vaccine groups that received two intramuscular injections with either mRNA ( $2 \mathrm{x}$ RNA) or an adenoviral vector (2x Ad5) reflecting current SARS-CoV-2 vaccination strategies were included (Fig. 5A). These experiments were performed in C57BL/ 6 mice to allow correlations to efficacy data in K18-hACE2 mice.

Four weeks after the boost immunization, all vaccinated animals reached high levels of anti-S IgG in the serum (Fig. 5B and Supplementary Fig. 5). However, the anti-S IgG levels after the homologous RNA vaccination were significantly higher than in all other groups. Interestingly, this order does not reflect the anti-S response measured four weeks after the prime immunization. Here, the intramuscular injection of Ad5 induced the highest antibody levels, most probably by inducing more potent IgG2a responses than the RNA vaccine (Supplementary Fig. 6). Contrary, the IgG levels detected in BALs were higher in the groups receiving the intranasal Ad5 boost vaccination (Fig. 5B). 

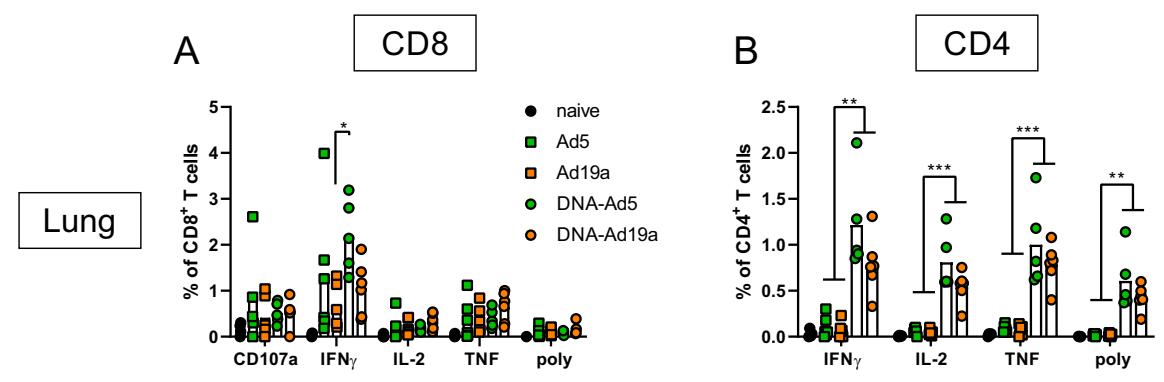

C

D
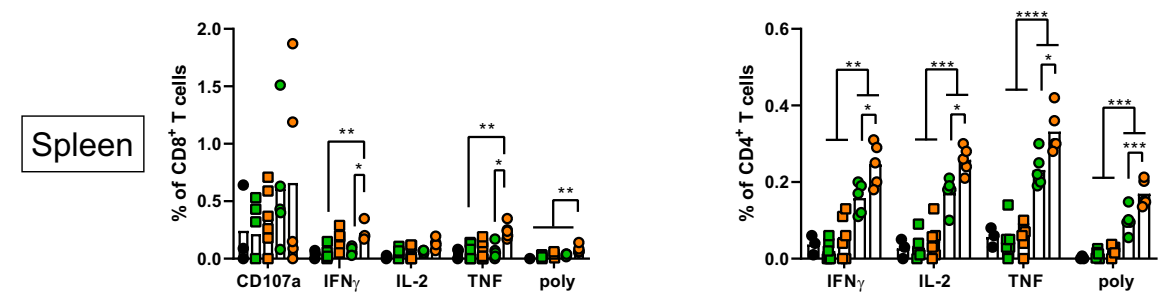

Fig. 4 Spike-specific $\mathbf{T}$ cell responses after intranasal immunization with Ad5- or Ad19a-based viral vector vaccines. $B A L B / c$ mice were vaccinated according to Fig. 1A. Lung and spleen homogenates were restimulated with peptide pools covering major parts of $\mathrm{S}$. The responding CD8+ $(\mathbf{A}$ and $\mathbf{C})$ and CD4 ${ }^{+} \mathrm{T}$ cells (B and $\mathbf{D}$ ) were identified by intracellular staining for accumulated cytokines or staining for CD107a as degranulation marker. The gating strategy is shown in Supplementary Fig. 3. Bars represent group means overlaid with individual data points; naïve $n=4$ (exception: $n=3$ in C and D); DNAAd5 $n=5$; other groups $n=6$. Data were analysed by one-way ANOVA followed by Tukey's multiple comparison test. Statistically significant differences are indicated only among the different vaccine groups; $p$ values indicate significant differences $\left({ }^{\star} p<0.05 ;{ }^{\star \star} p<0.005 ;{ }^{\star \star \star} p<0.0005 ;{ }^{\star \star \star \star} p<0.0001\right)$. poly; polyfunctional $\mathrm{T}$ cell population positive for all assessed markers.

A

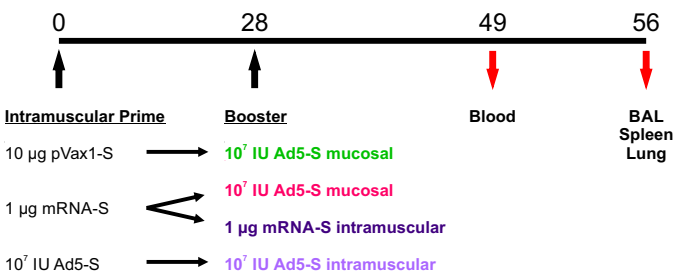

B

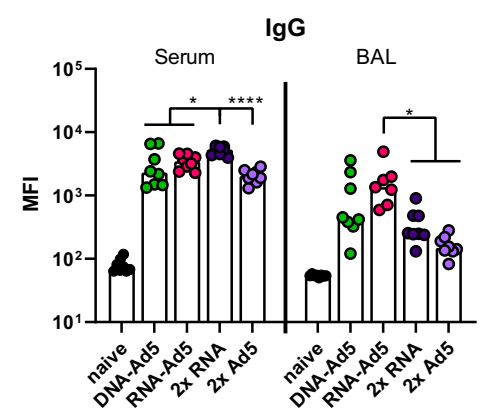

C

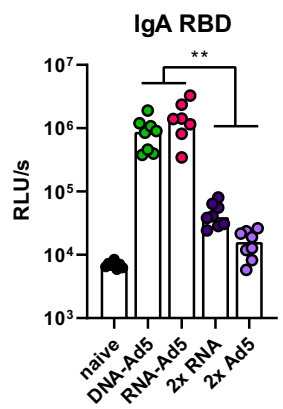

D

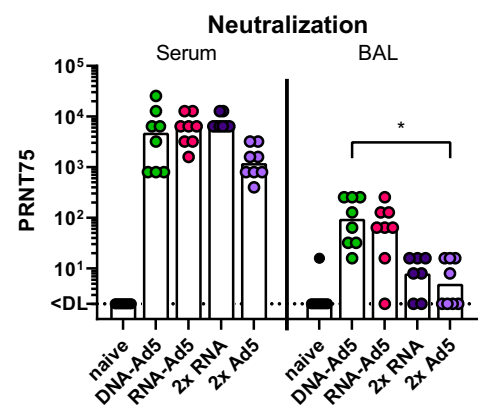

Fig. 5 Humoral responses after homologous or heterologous prime-boost vaccination. A C57BL/ 6 mice received an intramuscular prime immunization with the spike-encoding DNA $(10 \mu \mathrm{g})$, Ad5-S ( $10^{7}$ infectious units), or the mRNA vaccine, Comirnaty ${ }^{\oplus}(1 \mu \mathrm{g})$. Mice from the heterologous prime-boost groups were boosted four weeks later intranasally with Ad5-S ( $10^{7}$ infectious units). The homologous prime-boost groups received a second dose of mRNA $(1 \mu \mathrm{g})$ or Ad5-S (107 infectious units) intramuscularly. Serum antibody responses were analysed 21 days and mucosal immune responses four weeks after the boost immunizations. Spike-specific lgG (B) were assessed by a flow cytometric approach (dilutions: Sera 1:800, BAL 1:20). BAL samples were tested for spike-specific IgA directed against RBD by ELISA (C). Plaque reduction neutralization titres (PRNT75) were determined by in vitro neutralization assays (D). Bars represent group medians overlaid with individual data points; sera all groups $n=8$; BALs RNA-Ad5 $n=7$, other groups $n=8$ (out of two independent experiments). Data were analysed by one-way ANOVA followed by Tukey's post test (B and C) or Kruskal-Wallis test (one-way ANOVA) followed by Dunn's multiple comparison test (D). Statistically significant differences are indicated only among the different vaccine groups; $p$ values indicate significant differences $\left({ }^{\star} p<0.05 ;{ }^{* \star} p<0.005 ;{ }^{* \star *} p<0.0005 ;{ }^{* \star \star *} p<0.0001\right)$. 
A

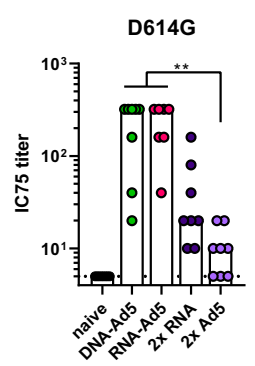

B

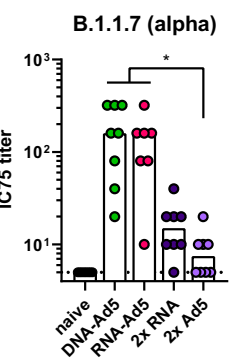

C

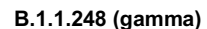

D

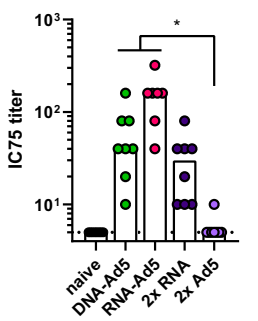

E

B.1.351 (beta)

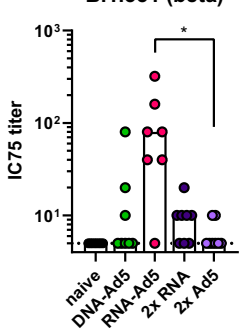

B.1.617.2 (delta)

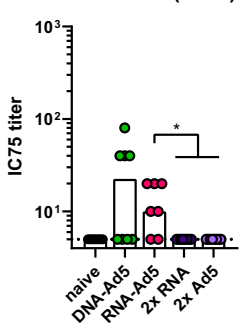

Fig. 6 Neutralization of SARS-CoV-2 variants. C57BL/6 mice were vaccinated according to Fig. 5A. BAL samples were analysed by pseudotype neutralization assays for the neutralization of different SARS-CoV-2 variants (A-E). Data points were shown for individual animals and bars represent group medians; RNA-Ad5 $n=7$, other groups $n=8$ (out of two independent experiments). The dashed line indicates the lower limit of detection. Data were analysed by Kruskal-Wallis test (one-way ANOVA) followed by Dunn's multiple comparison. Statistically significant differences are indicated only among the different vaccine groups; $p$ values indicate significant differences $\left({ }^{\star} p<0.05 ;{ }^{\star \star} p<0.005 ;{ }^{\star \star \star} p<0.0005 ;{ }^{\star \star \star \star} p<0.0001\right)$.

In addition, significantly increased local IgA antibody levels could be detected for both groups in a RBD-specific ELISA (Fig. 5C). On a functional level, the higher amounts of RBD-specific antibodies were mirrored by higher neutralizing capacities in the BALs of the groups DNA-Ad5 or RNA-Ad5 (Fig. 5D). Interestingly, the high amount of neutralizing antibodies in the sera were not significantly different among the vaccine groups independent of the route of the boost immunization.

Since mucosal antibodies might be most important for preventing an initial infection and thereby transmission, we evaluated the protective capacity against SARS-CoV-2 variants in pseudotype-based virus neutralization assays (Fig. 6). Here, the most robust and broadest responses were detected in the BALs of RNA-Ad5 treated animals with decreasing neutralizing potencies against spike proteins from SARS-CoV-2 lineages D614G to B.1.1.7 (alpha variant)/P.1 (gamma variant) to B.1.351 (beta variant), and finally B.1.617.2 (delta variant). Interestingly, the RNA-Ad5 and DNA-Ad5 schemes resulted in comparable IC75 titres against alpha and delta, but DNA-Ad5 was less potent against the beta variant. This might reflect the different nature of the encoded $S$ protein sequences. Finally, the solely systemic vaccination schedules provoked 4- to 32-fold lower titres of mucosal neutralization against D614G, alpha, beta, and gamma, whereas no neutralization of delta spike-pseudotyped reporter virus could be observed. These data underline the importance of mucosal immunizations in order to provide immediate neutralization of incoming virus at the entry site.

Lung-resident memory $\mathrm{T}$ cells are efficiently established by a mucosal boost but not by conventional mRNA vaccination. Next, we assessed the induction of systemic and resident $T$ cell memory. Antigen-experienced CD $44^{+} \mathrm{CD} 8^{+} \mathrm{T}$ cells isolated from lung tissue were quantitatively most pronounced in the $2 \mathrm{x}$ RNA group (Fig. 7B). However, by analysing the contribution of tissueresident (iv-) and vascular (iv+) compartments, a more complex picture emerged. The groups that received two systemic immunizations almost exclusively mounted circulating $\mathrm{T}$ cell memory (>95\% iv+; Fig. 7A, B) and consistent to this, the predominant memory phenotypes were $\mathrm{T}_{\mathrm{EFF}}, \mathrm{T}_{\mathrm{EM}}$, and $\mathrm{T}_{\mathrm{CM}}$ (Fig. $7 \mathrm{C}$ ). $\mathrm{CD} 103^{+} \mathrm{CD} 69^{+} \mathrm{T}_{\mathrm{RM}}$ were not established in the lungs of these animals. In complete contrast, the DNA-Ad5 immunized animals displayed mostly $\mathrm{T}_{\mathrm{RM}}$ but were lacking substantial numbers of circulating memory cells. Importantly, the RNA-Ad5 strategy induced the most comprehensive $\mathrm{T}$ cell memory consisting of both circulating subsets and $\mathrm{CD}_{103}{ }^{+} \mathrm{CD} 69^{+} \mathrm{T}$ cells in the lung.

The analysis of spike-specific, cytokine producing $\mathrm{CD}^{+} \mathrm{T}$ cells showed a similar compartmentalization. Although the overall numbers of $\mathrm{CD}_{107 \mathrm{a}^{+}}, \mathrm{IFN} \gamma^{+}$, and $\mathrm{TNF}^{+} \mathrm{CD} 8^{+} \mathrm{T}$ cells were highest in the lungs of the 2x RNA group, these cells were almost exclusively found in the vascular compartment (iv-labelled, Fig. 8A-C). The same is true for the homologous immunization with Ad5, albeit reaching much lower percentages of reactive cells. In line with the phenotypic analyses, RNA-Ad5 induced both systemic and local $\mathrm{T}$ cell responses, whereas DNA-Ad5 provoked mainly $\mathrm{T}_{\mathrm{RM}}$. The trends observed for $\mathrm{CD}^{+} \mathrm{T}$ cell responses in the iv-labelled lung population were largely mirrored by the splenic responses (Fig. 8D), further underlining that the former population reflects circulating $\mathrm{T}$ cells present in the lung vasculature at the time of sampling. Spike-specific, tissue-resident $\mathrm{CD}^{+} \mathrm{T}$ cell responses were also effectively established by the mucosal boost strategies (Fig. 9A, B) and systemic IFN $\gamma$ producing $\mathrm{CD}^{+} \mathrm{T}$ cells in the spleen were induced by all vaccine schedules with two RNA shots being the most effective strategy (Fig. 9D).

In conclusion, only intranasal vaccination schedules were able to induce profound mucosal immunity in the respiratory tract consisting of neutralizing $\operatorname{IgG}, \operatorname{IgA}$, and lung $\mathrm{T}_{\mathrm{RM}}$. Compared to DNA-Ad5, the RNA-Ad5 strategy provoked a more efficient neutralization of VOCs and established a comprehensive $\mathrm{T}$ cell immunity consisting of both $\mathrm{T}_{\mathrm{RM}}$ and circulatory $\mathrm{T}$ cells.

Systemic and mucosal vaccine schedules effectively protect from experimental SARS-CoV-2 infection. In order to assess the protective efficacy of the vaccination strategies, human ACE2 transgenic mice (K18-hACE2) were immunized as described before and challenged four weeks after the boost immunization with $9 \times 10^{3} \mathrm{FFU}$ of the SARS-CoV-2 strain BavPat1 as previously described $^{56}$. Since the $2 \mathrm{x}$ Ad5 immunization was less immunogenic than the $2 \mathrm{x}$ RNA immunization, this group was replaced by another $2 \mathrm{x}$ Ad vaccination regime consisting of an intramuscular Ad19a prime followed by the established intranasal Ad5 boost (Fig. 10A). Seven out of eight unvaccinated control animals reached humane endpoints at day five indicating a severe and lethal course of the disease (Fig. 10B). They presented weight loss starting at day four post-infection with a concomitant increase of clinical signs (Fig. 10C, D). In contrast, all vaccinated groups were largely protected from weight loss, clinical signs of disease, and mortality (Fig. 10B-D). High levels of viral RNA in lung homogenates and BAL fluids were only detected in unvaccinated animals indicating efficient viral replication, while from the vaccinated animals only two of the $2 x$ RNA group had viral RNA copy numbers in the lung above the detection limit (Fig. 10E). Similarly, infectious virus was retrieved from the lungs of unvaccinated animals but not from the immunized groups 
A

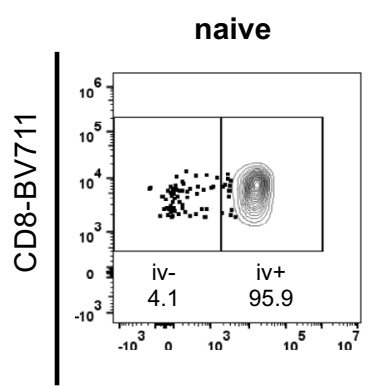

DNA-Ad5

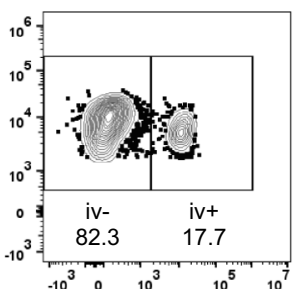

RNA-Ad5

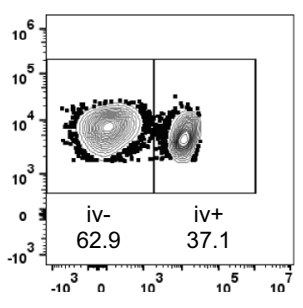

2x RNA

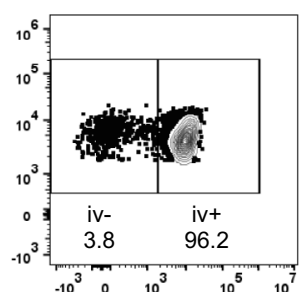

2x Ad5

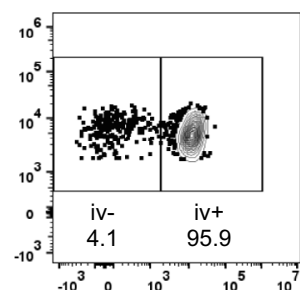

CD45-BV510 (i.v.)

B

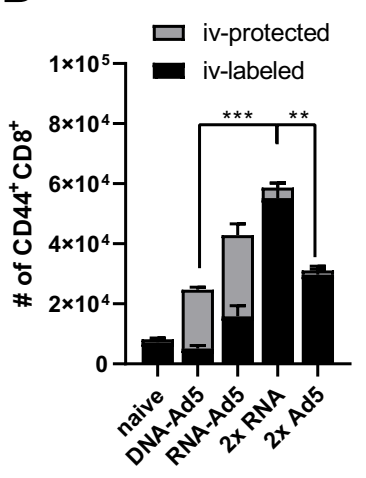

C

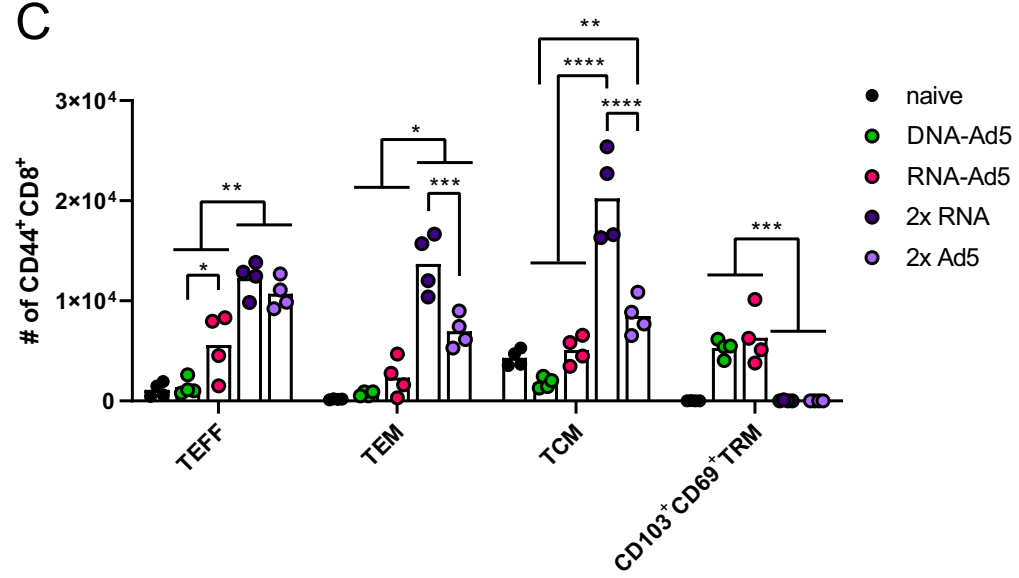

Fig. 7 Circulating and tissue-resident memory $\mathbf{T}$ cell subsets in the lung. C57BL/6 mice were vaccinated according to Fig. 5A. Antigen-experienced CD8 ${ }^{+}$ T cells were identified by CD44 staining and intravascular staining was used to differentiate between circulating (iv-labelled) and tissue-resident (ivprotected) memory cells. Representative contour plots are shown in (A). B The total number of $\mathrm{CD} 44^{+} \mathrm{CD}^{+}+$with the relative contribution of iv - and iv + cells are summarized for each group. $\mathbf{C}$ Within the iv-labelled $C D 44^{+} \mathrm{CD} 8^{+}$population, effector $T$ cells $\left(T_{\mathrm{EFF}}\right.$; $\mathrm{CD} 127^{-} \mathrm{KLRG1}^{+}$), effector memory $T$ cells $\left(\mathrm{T}_{\mathrm{EM}} ; \mathrm{CD} 127^{+} \mathrm{KLRG}^{+}\right)$, and central memory $\mathrm{T}$ cells $\left(\mathrm{T}_{\mathrm{CM}} ; \mathrm{CD} 127^{+} \mathrm{KLRG1}^{-} \mathrm{CD} 69^{-} \mathrm{CD} 103^{-}\right)$were defined. Within the iv-protected population, $\mathrm{T}_{\mathrm{RM}}$ cells were defined as $\mathrm{KLRG}^{-} \mathrm{CD} 103^{+} \mathrm{CD} 69^{+}$. The gating strategy is shown in Supplementary Fig. 2. Bars represent group means overlaid with individual data points; all groups $n=4$. Data were analysed by one-way ANOVA followed by Tukey's multiple comparison test. Statistically significant differences are indicated only among the different vaccine groups; $p$ values indicate significant differences $\left({ }^{\star} p<0.05 ;{ }^{\star \star} p<0.005 ;{ }^{\star \star \star} p<0.0005 ;{ }^{\star \star \star \star} p<0.0001\right)$.

Representative data from one out of three independent experiments with slightly different end time points are shown.

(Fig. 10F). Due to the nature of this challenge model, high viral RNA copy numbers were also detected in the brains of naïve animals (Supplementary Fig. 7). Although viral RNA was still detectable in the brains of most vaccinated animals, the copy numbers were reduced by $4-5$ logs, and no significant differences among the vaccine groups could be seen.

Taken together, the mucosal boost strategies were able to fully prevent mortality and symptomatic disease upon experimental SARS-CoV-2 infection. The protective efficacy was equal to the current approved vaccination regimen consisting of two intramuscular injections of Comirnaty.

\section{Discussion}

The SARS-CoV-2 pandemic had and still has a deep impact on social, economic, and healthcare aspects of the world community. As a reaction, academic institutions, biotech companies, and regulatory agencies released safe and effective vaccines in an unprecedented speed. While early in the pandemic the vaccine efficacies of the respective vaccine schedules were in focus, the interest now shifts towards investigating immunogenicity and efficacy of mixed modality vaccinations, the maintenance of long-term immunity, and the protection against emerging variants. So far, the heterologous combination of different vaccine modalities is mostly connected to a superior immunogenicity in preclinical ${ }^{57,58}$ and clinical studies ${ }^{59-62}$. As now most countries with progressed vaccination campaigns discuss the employment of booster vaccinations, a possible next step might be the implementation of mucosal immunizations in order to harness the full potential of mucosal immunity at the entry port of SARS-CoV-2 infections.

To this end, the current study determined the immunogenicity and protective efficacy of mucosal boost vaccination with replication-incompetent adenoviral vectors after systemic prime immunizations with a DNA vaccine or an mRNA vaccine that is part of the current vaccine campaigns. The results clearly prove a potent induction of mucosal immune responses by these heterologous strategies not seen after purely systemic immunization schedules. Concomitantly, we observed comparable protective efficacies upon experimental infection among systemic immunization schedules and the heterologous mucosal boost strategies. These results should encourage the exploitation of mucosal booster immunizations as a non-traumatic vaccination modality able to induce strong mucosal immunity in addition to systemic responses. Although not discernible in the present study, this front-line immunity might further inhibit breakthrough infections and transmission risk. 
A

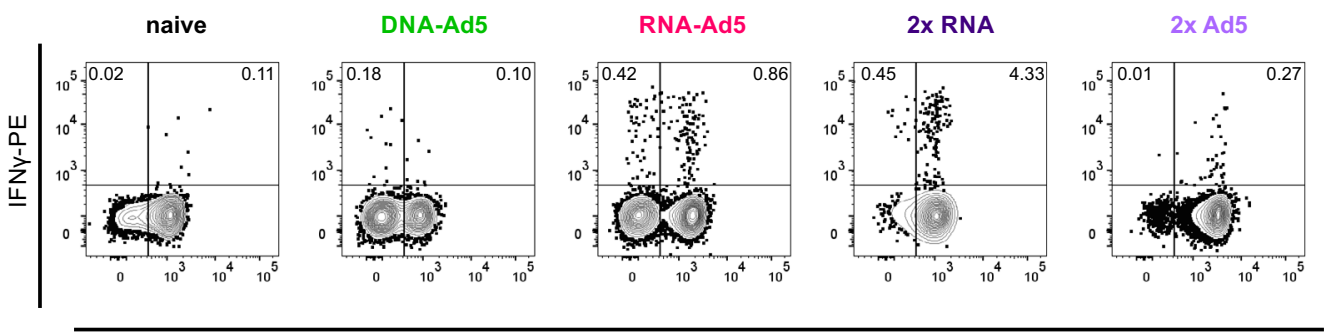

CD45-BV510 (i.v.)
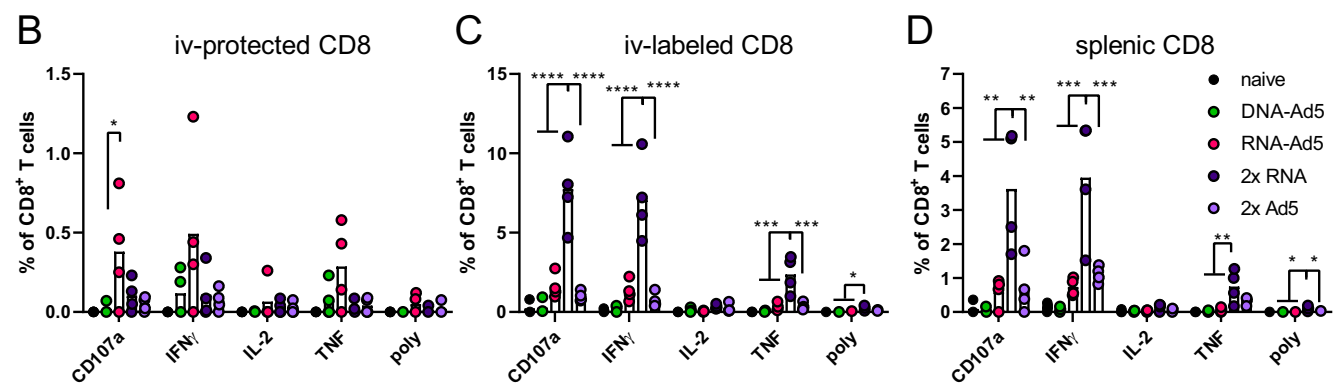

Fig. 8 Spike-specific CD8 ${ }^{+}$T cell responses. C57BL/6 mice were vaccinated according to Fig. 5A. Lung (B and C) and spleen homogenates (D) were restimulated with a peptide pool covering major parts of $\mathrm{S}$. The responding $\mathrm{CD} 8^{+} \mathrm{T}$ cells were identified by intracellular staining for accumulated cytokines or staining for CD107a as degranulation marker. A Representative contour plots showing IFN $\gamma$ production in iv + and iv - lung CD8 ${ }^{+} \mathrm{T}$ cells. The gating strategy is shown in Supplementary Fig. 3. Bars represent group means overlaid with individual data points; all groups $n=4$ (exception: $n=3$ for DNA-Ad5 in D). Data were analysed by one-way ANOVA followed by Tukey's multiple comparison test. Statistically significant differences are indicated only among the different vaccine groups; $p$ values indicate significant differences $\left({ }^{\star} p<0.05 ;{ }^{\star \star} p<0.005 ;{ }^{\star \star \star} p<0.0005 ;{ }^{\star \star \star \star} p<0.0001\right)$. poly; polyfunctional T cell population positive for all assessed markers. Representative data from one out of three independent experiments with slightly different end time points are shown.

\section{A}

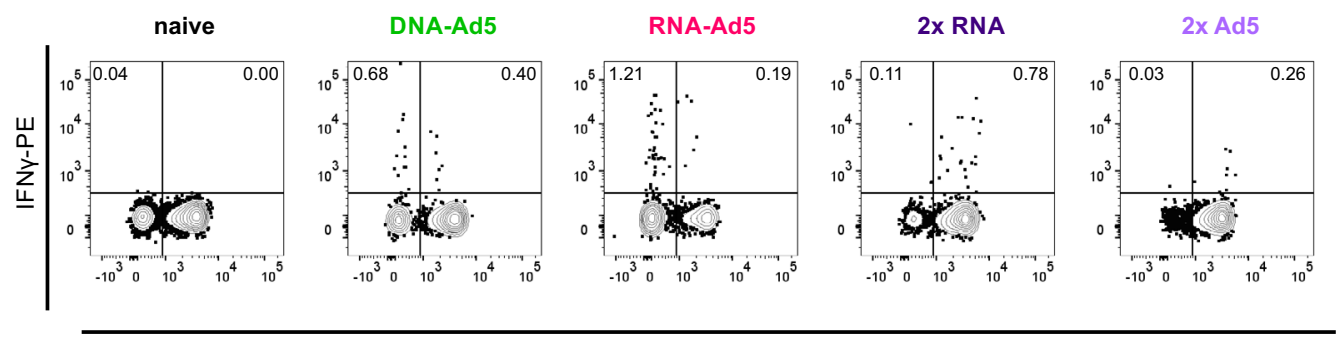

CD45-BV510 (i.v.)
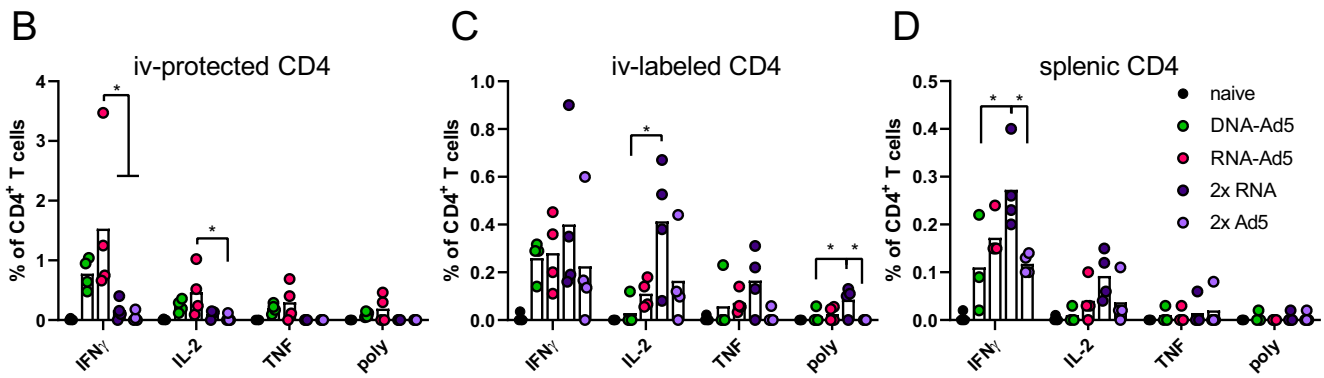

Fig. 9 Spike-specific CD4 ${ }^{+}$T cell responses. C57BL/6 mice were vaccinated according to Fig. 5A. Lung (B and C) and spleen homogenates (D) were restimulated with a peptide pool covering major parts of $\mathrm{S}$. The responding CD4 ${ }^{+} \mathrm{T}$ cells were identified by intracellular staining for accumulated cytokines. A Representative contour plots showing IFN $\gamma$ production in iv + and iv- lung CD4+ T cells. The gating strategy is shown in Supplementary Fig. 3. Bars represent group means overlaid with individual data points; all groups $n=4$ (exception: $n=3$ for DNA-Ad5 in D). Data were analysed by one-way ANOVA followed by Tukey's multiple comparison test. Statistically significant differences are indicated only among the different vaccine groups; $p$ values indicate significant differences $\left({ }^{\star} p<0.05 ;{ }^{\star \star} p<0.005 ;{ }^{\star \star \star} p<0.0005 ;{ }^{\star \star \star \star} p<0.0001\right)$. poly; polyfunctional T cell population positive for all assessed markers. Representative data from one out of three independent experiments with slightly different end time points are shown. 
A

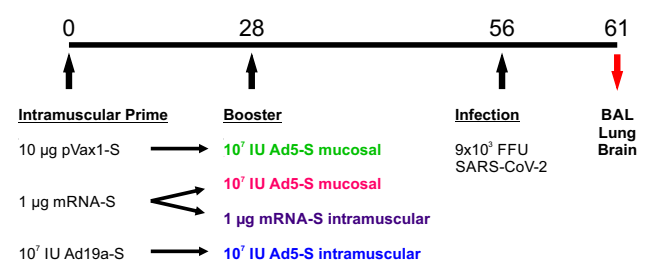

C

Body weight

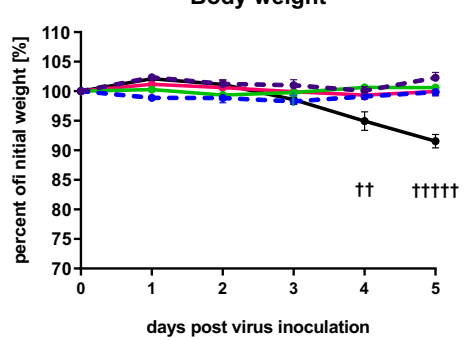

$\mathrm{E}$

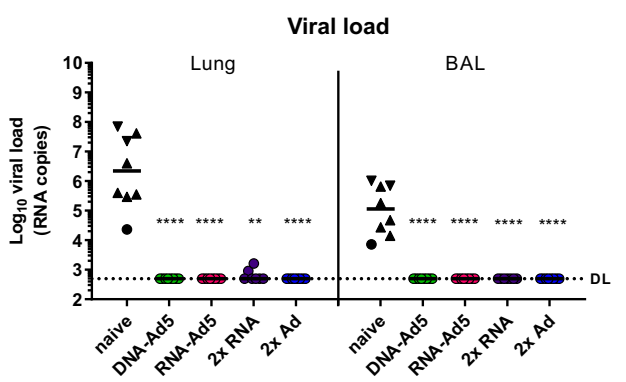

B

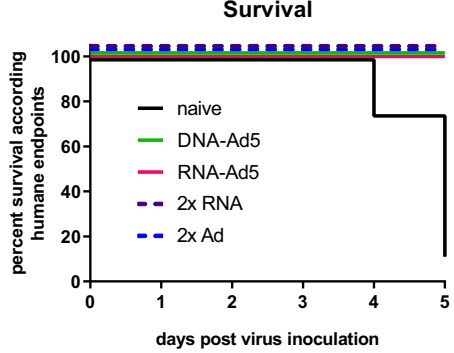

D

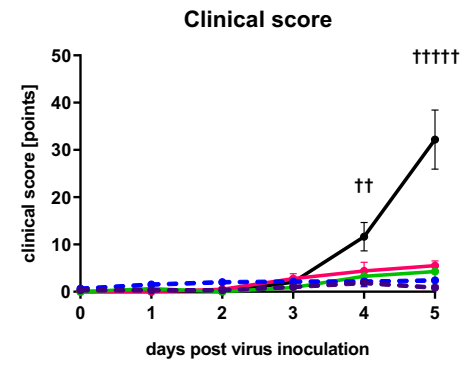

$\mathrm{F}$

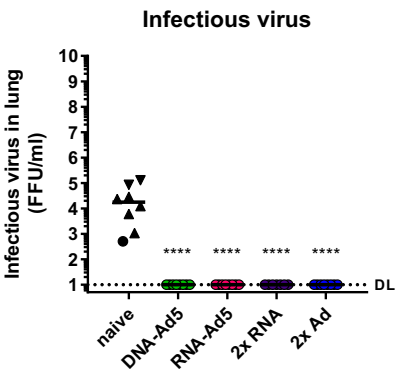

Fig. 10 Protective efficacy against SARS-CoV-2 infection. A K18-hACE2 mice ( $2 x$ RNA $n=7$, other groups $n=8$ ) received an intramuscular prime immunization with the spike-encoding DNA $(10 \mu \mathrm{g})$ followed by electroporation, Ad19a-S (107 infectious units), or the mRNA vaccine, Comirnaty ${ }^{\oplus}(1 \mu \mathrm{g})$. Mice from the heterologous prime-boost groups were boosted four weeks later intranasally or intramuscularly with Ad5-S (107 infectious units). The $2 x$ RNA group received a second dose of mRNA $(1 \mu \mathrm{g})$ intramuscularly. Four weeks after the boost immunization, mice were infected intranasally with $9 \times 10^{3}$ FFU SARS-CoV-2. All animals were monitored daily for survival (B), body weight (C), and clinical score (D). Curves in (C) and (D) represent group means with SEM. Animals reaching humane endpoints were euthanized and are marked by a cross at the respective time point. Viral RNA copy numbers were assessed in lung homogenates and BAL samples by qRT-PCR (E) and infectious virus was retrieved and titrated from lung homogenates (F). Data points shown represent viral copy number or virus titre of each animal with the median of each group, whereby circles indicate a survival of 5 days post infection and triangles indicates euthanized mouse according humane endpoints at day 4 (triangle pointing down) or day 5 (triangle pointing up). The dashed line indicates the lower limit of detection. Data were analysed by Kruskal-Wallis test (one-way ANOVA) and Dunn's Pairwise Multiple Comparison Procedures as post hoc test in comparison to PBS control; $p$ values indicate significant differences $\left({ }^{\star} p<0.05 ;{ }^{\star \star} p<0.005 ;{ }^{\star \star \star} p<0.0005 ;{ }^{* \star \star \star} p<0.0001\right)$.

In the first part of the present study, we confirmed that a systemic prime with a plasmid DNA vaccine potentiates the immunogenicity of mucosally applied adenoviral vector vaccines $^{63}$. Most probably, systemic memory cells induced by the priming expand during the recall response and are then recruited to the mucosal site to differentiate into tissue-resident memory cells as reported for $\mathrm{T}_{\mathrm{RM}}$ in the female reproductive tract ${ }^{64}$. This is an important finding since it clearly proves the suitability to implement mucosal immunizations into current SARS-CoV-2 vaccination schedules.

Similar to our observations, other preclinical studies imply significant protection against SARS-CoV-2 in mice, hamsters, ferrets, and non-human primates after an intranasal vaccination with adenoviral vector vaccines ${ }^{47-49,51,65}$. Hassan and colleagues showed that a single intranasal immunization with ChAd-SARS$\mathrm{CoV}-2-\mathrm{S}$ is superior to an intramuscular immunization with the same vaccine in regard to virus replication in the lower respiratory tract ${ }^{47}$. They report similar findings in rhesus macaques as well, but in this animal model early virus replication in the upper respiratory tract was less affected by a mucosal vaccination $^{48}$. Importantly, these studies did not assess heterologous prime-boost-strategies, which may increase the immunogenicity of the mucosal vaccination further and thereby might reduce early virus replication more effectively. Along these lines, the first data from a human clinical trial with an intranasal Ad5based SARS-CoV-2 vaccine, Altimmune's AdCOVID, were disappointing and the development was discontinued ${ }^{52}$. Although safe and well tolerated, the vaccine did not demonstrate sufficient immunogenicity after one or two intranasal doses in previously unvaccinated individuals. The data from a very recent clinical phase I trial underline these findings by providing that serum antibody levels were lower after two intranasal doses of an Ad5based SARS-CoV-2 vaccine than after one single intramuscular injection ${ }^{53}$. However, the combination of a mucosal booster 
immunization with an intramuscular prime resulted in the highest levels of neutralising antibodies reported in that clinical trial. Unfortunately, mucosal immune responses were not assessed. These observations might support our notion of the potential need of pre-existing memory cells to maximize the immunogenicity of an intranasal immunization. While this might seem to complicate the use of nasal vaccines at first sight, one has to keep in mind that mass vaccination campaigns currently employ intramuscular immunizations in large parts of the community. Such heterologous vaccine strategies will finally result in a balanced response between systemic and mucosal immunity.

In most mucosal parameters observed, Ad19a was less immunogenic compared to Ad5, whereas systemic responses, especially $\mathrm{CD} 4^{+} \mathrm{T}$ cell responses, were more efficiently induced. We reported this trend before and speculate that different tropisms of the viral vectors might account for that: Ad5 enters cells via binding to the coxsackie-and-adenovirus receptor (CAR), while Ad19a binds sialic acids and CD46 as entry receptors ${ }^{66-69}$. Since these molecules are differentially expressed on stromal and immune cells, this might be one aspect explaining the different local and systemic immune profiles. Importantly, also licensed adenoviral SARS-CoV-2 vaccines differ in their entry receptor usage. While AstraZeneca's Vaxzevria ${ }^{\circledast}$ (ChAdOx1) utilizes CAR as primary receptor, Janssen's Ad26.COV2.S enters cells via binding to $\mathrm{CD} 46^{70}$. Thus, based on our observations, ChAdOx1 might be a good choice for mucosal immunizations, while Ad26 might be better suited for systemic vaccinations. Of note, the E1/ E3 deletions to render adenoviral vectors replication-incompetent are similar among our Ad5/Ad19a vectors and the licensed Ad26 and ChAdOx1 vaccines.

In the second part of the present study, the impact of the systemic priming modality (mRNA/plasmid DNA) on the immunogenicity and efficacy of intranasal boost vaccinations with Ad5 was investigated and compared to two systemic immunizations with Ad5 or RNA. Humoral responses in the serum were largely comparable among all groups with the exception that two doses Ad5 provoked weaker responses. It is tempting to speculate that anti-vector immunity induced by the primary immunization might have dampened the effect of the homologous booster. This phenomenon is also discussed in the context of the lower vaccine efficacy in humans reported with two standard doses Vaxzevria ${ }^{\oplus}$ (ChAdOxl) compared to the low dose-standard dose schedule ${ }^{5}$.

Mucosal antibody levels were higher in the groups having received a mucosal boost compared to the repeated systemic vaccination regimens. In regard to the levels of mucosal IgG, this trend was less pronounced as for mucosal IgA levels, presumably because serum IgG can be transudated into the respiratory lumen, whereas IgA is more stringently connected to a local immune reaction. Most importantly, the increased antibody responses in the mucosa also translated into more efficient virus neutralization by BAL samples. Only BAL samples from groups with mucosal vaccinations displayed neutralization of all tested VOCs. Although definitive evidence is currently missing, mucosal virus neutralization might be key to supress initial infections with SARS-CoV-2 and therefore minimize the risk of transmission to and by vaccinees. Interestingly, we observed distinct neutralization profiles between the DNA-Ad5 and RNA-Ad5 schemes probably originating from the use of different spike antigens. Thus, it is important to investigate the role of the prefusion conformation stabilization ${ }^{71}$ regarding neutralization profiles in more detail.

An important advantage of intranasally administered genetic vaccines is the induction of $\mathrm{T}_{\mathrm{RM}}$ in the respiratory tract. In the present study, tissue-resident memory was exclusively established by mucosal vaccinations. This is congruent with published research showing that local antigen expression is essential for the development of respiratory $\mathrm{T}_{\mathrm{RM}}{ }^{30,32,40}$. Moreover, in combination with a mucosal boost, a priming immunization with mRNA provoked a broader cellular immunity compared to a plasmid DNA prime consisting of not only $\mathrm{T}_{\mathrm{RM}}$ in the lung but also of significant numbers of circulating memory $\mathrm{T}$ cells. We speculate that such comprehensive $\mathrm{T}$ cell immunity is more effective against breakthrough infections than having only circulating or only resident $\mathrm{T}$ cells. Although the chosen challenge model in K18-hACE2 mice did not allow to decipher different degrees of protection, it implies that heterologous prime-boost vaccinations with an intranasal component are at least as protective as the currently licensed vaccine schedules. To further investigate potential advantages of mucosal immune responses, upcoming studies must mimic the settings more closely that likely contribute to breakthrough infections in vaccinated individuals: age $^{72}$, comorbidities ${ }^{73,74}$, waning immunity, and infection with less neutralization-sensitive variants like B.1.617.2 $2^{12-18}$. However, experimental human challenge studies with a small number of participants might also illuminate this topic similar to challenge studies previously performed in the context of $\mathrm{RSV}^{45,46}$ or Influenza ${ }^{75,76}$.

Absolute or mechanistic correlates of protection against SARSCoV-2 are not yet determined, although neutralizing antibody responses in sera were recently described to be predictive of protection against symptomatic infections ${ }^{77,78}$. However, limiting the initial infection rate by mucosal $\operatorname{IgA}$ and an early control of viral replication by local CD8 ${ }^{+} \mathrm{T}_{\mathrm{RM}}$ would add another layer of protection, which may be underestimated so far. Furthermore, the rapid inhibition of local replication may result in reduced levels of pro-inflammatory cytokines that partially contribute to tissue damage and severe disease progression ${ }^{79}$. In face of the encouraging results from the mixed vaccine regimens using a mRNA vaccine first followed by adenoviral vector vaccines ${ }^{59-62}$, it might be worthy to utilize an intranasal application for the viral vector boost immunization. This atraumatic, non-invasive application might also reduce the systemic side effects reported for the viral vector vaccines 80,81 .

Finally, we demonstrated that the heterologous mRNA prime/ intranasal Ad5 boost immunization is not inferior to the common gold standard of two intramuscular mRNA immunizations in regard to efficacy and additionally results in an unmatched mucosal immune response to SARS-CoV-2. Thus, this study provides the basis to pursue further efficacy studies in nonhuman primate models or even initiate clinical phase I studies using the currently available vaccines.

The induction of mucosal front-line immunity by heterologous vaccination strategies has the potential to mitigate current and future respiratory virus epidemics and pandemics. While maximizing the individual protection against breakthrough infections, it likely also decreases disease severity and the risk for virus transmission upon infections.

\section{Methods}

Ethics statement. The study was approved by the Government of Lower Franconia, which nominated an external ethics committee that authorized the experiments. Studies were performed under the project license AZ 55.2.2-2532-2-1179. The infection experiments were approved by local authorities after review by an ethical commission (TVV21/20).

Vaccines. Codon-optimized sequences for the $\mathrm{N}$ or the spike $\mathrm{S}$ protein of SARS$\mathrm{CoV}-2$ were cloned into the pVAX1 expression plasmid (ThermoFisher) optimized for plasmid DNA vaccinations referred to as pVAX1-SARS2-N and pVAX1-

SARS2- $S^{82}$. The encoded $S$ protein is the non-stabilized wildtype protein and based on the sequence of the initial Wuhan isolate (NCBI Reference Sequence: NC_045512.2; https://www.ncbi.nlm.nih.gov/nuccore/1798174254). Replicationdeficient $(\Delta \mathrm{E} 1 \Delta \mathrm{E} 3)$ adenoviral vector vaccines based Ad5 or Ad19a/64 encoding the same antigens were produced as previously described ${ }^{83}$ by Sirion Biotech 
(Martinsried, Germany). In both vector systems, antigen expression is initiated from a CMV-immediate/early-1-promoter and a bovine BGH polyadenylation signal provides transcription termination. The mRNA vaccine Comirnaty encodes the stabilized prefusion S protein and is described elsewhere ${ }^{84}$

Immunizations. Six to eight weeks old female BALB/cJRj or C57BL/6 mice were purchased from Janvier (Le Genest-Saint-Isle, France) and housed in individually ventilated cages in accordance with German law and institutional guidelines under specific pathogen-free (SPF) conditions, with constant temperature $\left(20-24^{\circ} \mathrm{C}\right)$ and humidity $(45-65 \%)$ on a $12 \mathrm{~h} / 12 \mathrm{~h}$-light/dark cycle. Experimental and control animals were co-housed. The research staff was trained in animal care and handling in accordance to the FELASA and GV-SOLAS guidelines. For intramuscular immunizations, inhalative isoflurane anaesthesia was applied and the vaccines were injected in a volume of $30 \mu \mathrm{PBS}$ in the musculus gastrocnemius of each hind leg. In case of DNA immunizations, the injection was followed by electroporation as described previously ${ }^{85}$. Under general anaesthesia $(100 \mathrm{mg} / \mathrm{kg}$ ketamine and $15 \mathrm{mg} / \mathrm{kg}$ xylazine), intranasal immunizations were performed by slowly pipetting a volume of $50 \mu \mathrm{l}$ into one nostril containing the final vaccine dose. Blood was sampled from the retro-orbital sinus under light anaesthesia with inhaled isoflurane. For sampling BAL fluids, mice were killed and the lungs were rinsed twice with $1 \mathrm{ml}$ cold PBS through the cannulated trachea.

Antigen-specific antibody ELISA. Spike S1, S2, and RBD antibody responses were analysed by ELISA. To this end, ELISA plates were coated with $100 \mathrm{ng}$ of the respective peptide (RBD peptide provided by Diarect GmbH, Freiburg; S1 and S2 peptides kindly provided by Thomas Schumacher from Virion/Serion GmbH, Würzburg) in $100 \mu \mathrm{l}$ carbonate buffer ( $50 \mathrm{mM}$ carbonate/bicarbonate, $\mathrm{pH}$ 9.6) per well over night at $4{ }^{\circ} \mathrm{C}$. Free binding sites were blocked with $5 \%$ skimmed milk in PBS-T (PBS containing $0.05 \%$ Tween-20) for $1 \mathrm{~h}$ at RT. BAL samples were diluted in $2 \%$ skimmed milk in PBS-T and incubated on the plate for one hour at RT. After three washing steps with $200 \mu \mathrm{l}$ PBS-T, HRP-coupled anti-mouse IgA (dilution 1:5,000, Bethyl Laboratories) detection antibodies were added for $1 \mathrm{~h}$ at RT. Subsequently, the plates were washed seven times with PBS-T and after the addition of ECL solution, the signal was measured on a microplate luminometer (VICTOR X5, PerkinElmer) and analysed using PerkinElmer 2030 Manager software.

FACS-based antibody analysis. A modified version of our previously published serological assay was used ${ }^{54}$, in which stably transduced HEK 293 T cells express the antigen of interest. To analyse quantities of antigen-specific antibodies, $5 \times 10^{5}$ HEK 293 T cells producing SARS-CoV-2 spike or nucleocapsid were incubated for $20 \mathrm{~min}$ at $4{ }^{\circ} \mathrm{C}$ with the respective biological sample diluted in $100 \mu$ FACS-PBS (PBS with $0.5 \%$ BSA and $1 \mathrm{mM}$ sodium azide) to bind to spike protein on the surface, or in $100 \mu \mathrm{l}$ permeabilization buffer (0.5\% saponin in FACS-PBS) to bind to intracellular nucleocapsid protein. After washing with $200 \mu \mathrm{l}$ buffer, specific antibodies were bound with polyclonal anti-mouse Ig-FITC $\left(1: 300,4^{\circ} \mathrm{C}, 20 \mathrm{~min}\right.$ incubation; BD Biosciences), anti-mouse IgG1-APC (1:300, clone X56, Biolegend), or anti-mouse IgG2a-FITC (1:300, clone R19-15, BD Biosciences). After further washing, samples were measured on an AttuneNxt (ThermoFisher) and analysed using FlowJo software (Tree Star Inc.).

Virus neutralization assay. Serial dilutions of sera and BALs were incubated with 2000 PFU of an early SARS-CoV-2 isolate (GISAID EPI ISL 406862 Germany/ BavPat1/2020) in $100 \mu \mathrm{l}$ OptiPro medium supplemented with 1x GlutaMAX (both Gibco) for $1 \mathrm{~h}$ at $37^{\circ} \mathrm{C}$. Subsequently, the mixture was added onto a confluent monolayer of Vero E6 cells (seeded the day before at $10^{4}$ cells per well in a 96-well plate). After $1 \mathrm{~h}$, the mixture was removed from the cells and $100 \mu \mathrm{l}$ OptiPro medium supplemented with 1x GlutaMAX (both Gibco) was added. After $24 \mathrm{~h}$ incubation at $37^{\circ} \mathrm{C}$ and $5 \% \mathrm{CO}_{2}$, cells were fixed with $100 \mu \mathrm{l} 4 \%$ paraformaldehyde for $20 \mathrm{~min}$ at RT and permeabilized with $100 \mu \mathrm{l} 0.5 \%$ Triton X-100 in PBS for $15 \mathrm{~min}$ at RT. After a blocking step with $100 \mu \mathrm{l} \%$ skimmed milk in PBS for $1 \mathrm{~h}$ at RT, cells were stained with purified immunoglobulins from a SARS-CoV-2 convalescent patient in $2 \%$ skimmed milk for $1 \mathrm{~h}$ at $4{ }^{\circ} \mathrm{C}$. After three washing steps with $200 \mu \mathrm{l}$ PBS, $100 \mu \mathrm{l}$ of anti-human IgG FITC (1:200, Jackson Immunoresearch) were added diluted in $2 \%$ skimmed milk and incubated for $1 \mathrm{~h}$ at $4{ }^{\circ} \mathrm{C}$ in the dark. After another three washing steps with $200 \mu \mathrm{l}$ PBS, plaques were counted with an ELISPOT reader and analysed using CTL Immunospot software (Cellular Technology limited BioSpot). Infected wells without serum were used as reference to determine the $75 \%$ plaque reduction neutralization titre (PRNT75).

Pseudotype neutralization assay. Neutralization of various spike variants was assessed with the help of spike-pseudotyped simian immunodeficiency virus particles as described before ${ }^{86}$. For the production of pseudotyped reporter particles, HEK293T cells were transfected with the SIV-based self-inactivating vector encoding luciferase (pGAE-LucW), the SIV-based packaging plasmid (pAdSIV3), and the respective spike variant-encoding plasmid ${ }^{87-89}$. For this purpose, $2 \times 10^{7}$ HEK293T cells were seeded the day before in a $175 \mathrm{~cm}^{2}$ flask in Dulbecco's Modified Eagle's Medium (DMEM; Gibco) containing 10\% FCS, 2 mM L-Glutamine, and 100 units $/ \mathrm{ml}$ penicillin/streptomycin (D10 medium). The transfection mixture was prepared by mixing $20 \mu \mathrm{g}$ of each plasmid with $180 \mu \mathrm{g}$ polyethylenimine in $5 \mathrm{ml}$ DMEM without additives. $15 \mathrm{~min}$ later, the mixture was added to the cells. After $4-8 \mathrm{~h}$ incubation, the medium was exchanged to $25 \mathrm{ml}$ DMEM containing 1.5\% FCS, $2 \mathrm{mM}$ L-Glutamine, and $100 \mathrm{units} / \mathrm{ml}$ penicillin/ streptomycin. $72 \mathrm{~h}$ post-transfection, the supernatants containing the lentiviral particles were harvested, sterile filtrated $(0.45 \mu \mathrm{m}$ membrane), and stored at $-20^{\circ} \mathrm{C}$. HEK293T-ACE2 cells stably expressing the human Angiotensinconverting enzyme 2 (ACE2) were transduced with the dilutions of the pseudotypes. The amount of lentiviral particles resulting in luciferase signals of $2-10 \times 10^{4}$ $\mathrm{RLU} / \mathrm{s}$ were used for the latter assay.

For the assessment of pseudotype neutralization, HEK293T-ACE2 cells were seeded at $2 \times 10^{4}$ cells/well in $100 \mu \mathrm{l}$ D10 in a 96 well flat bottom plate. $24 \mathrm{~h}$ later, $60 \mu \mathrm{l}$ of serial dilutions of the BAL samples were incubated with $60 \mu \mathrm{l}$ lentiviral particles for $1 \mathrm{~h}$ at $37^{\circ} \mathrm{C}$. HEK293T cells were washed once with PBS and the particle-sample mix was added to the cells. $48 \mathrm{~h}$ later, medium was discarded and the cells lysed with $100 \mu \mathrm{l}$ Bright Glo lysis buffer (Promega) for $15 \mathrm{~min}$ at $37^{\circ} \mathrm{C}$. Three minutes later, after the addition of $25 \mu \mathrm{l}$ Bright Glo substrate (Promega), the luciferase signal was assessed on a microplate luminometer (VICTOR X5, PerkinElmer) and analysed using PerkinElmer 2030 Manager software. Neutralization titres are determined as the last reciprocal dilution that inhibits more than $75 \%$ of the luciferase signal measured in positive controls (inhibitors concentration $75 \%$, IC75).

$T$ cell assays. For the definition of circulatory and tissue-resident $\mathrm{T}$ cells, mice were injected with $3 \mu \mathrm{g}$ anti-CD45-BV510 (clone 30-F11, Biolegend) intravenously and were euthanized $3 \mathrm{~min}$ later with an overdose of inhaled isoflurane. Spleens and lungs were harvested. The latter ones were cut into small pieces followed by incubation for $45 \mathrm{~min}$ at $37^{\circ} \mathrm{C}$ with 500 units Collagenase D and 160 units DNase I in $2 \mathrm{ml} \mathrm{R10} \mathrm{medium} \mathrm{(RPMI} 1640$ supplemented with 10\% FCS, $2 \mathrm{mM}$ L-Glutamine, $10 \mathrm{mM}$ HEPES, $50 \mu \mathrm{M} \beta$-mercaptoethanol and $1 \%$ penicillin/streptomycin). Digested lung tissues and spleens were mashed through a $70 \mu \mathrm{m}$ cell strainer before the single cell suspensions were subjected to an ammonium-chloride-potassium lysis. One million splenocytes or $20 \%$ of the total lung cell suspension were plated per well in a 96-well round-bottom plate for in vitro restimulation and phenotype assays.

For the restimulation, samples were incubated for $6 \mathrm{~h}$ (or $24 \mathrm{~h}$ in case of Figs. 8 , 9) in $200 \mu \mathrm{l} \mathrm{R} 10$ medium containing monensin $(2 \mu \mathrm{M})$, anti-CD28 $(1 \mu \mathrm{g} / \mathrm{ml}$, eBioscience), anti-CD107a-FITC (1:200, clone eBio1D4B, eBioscience), and the respective SARS-CoV-2 peptide pool $(0.6 \mathrm{nmol} /$ peptide, $\mathrm{S}$ and $\mathrm{N}$ pools from Miltenyi Biotec, 130-126-701 and 130-126-699). Unstimulated samples were used for subtraction of background cytokine production. Cells were stained after the stimulation with anti-CD8a-Pacific blue (1:2000, clone 53-6.7, Biolegend), antiCD4-PerCP (1:2000, clone RM4-5, eBioscience) and Fixable Viability Dye eFluor ${ }^{\circ}$ 780 (1:4000, eBioscience) in FACS-PBS for $20 \mathrm{~min}$ at $4^{\circ} \mathrm{C}$. After fixation $(2 \%$ paraformaldehyde, $\left.20 \mathrm{~min}, 4^{\circ} \mathrm{C}\right)$ and permeabilization $(0.5 \%$ saponin in FACSPBS, $\left.10 \mathrm{~min}, 4^{\circ} \mathrm{C}\right)$, cells were stained intracellularly with anti-IL-2-APC (1:300, clone JES6-5H4, Biolegend), anti-TNF-PECy7 (1:300, clone MPG-XT22, Biolegend), and anti-IFNy-PE (1:300, clone XMG1.2, Biolegend). The gating strategy is shown in Supplementary Fig. 3.

For the phenotype analyses, cells were stained in FACS-PBS with anti-CD8BV711 (1:300, clone 53-6.7, BioLegend), anti-CD4-BV605 (1:1000, clone RM4-5, BioLegend), anti-CD127-FITC (1:500, clone A7R34, BioLegend), anti-CD69PerCP-Cy5.5 (1:300, clone H1.2F3, BioLegend), anti-CD103-PE (1:200, clone 2E7, eBioscience), anti-KLRG1-PE-Cy7 (1:300, clone 2F1, eBioscience), anti-CD44-APC (1:5000, clone IM7, BioLegend), and Fixable Viability Dye eFluor ${ }^{6} 780$ (1:4000, eBioscience). Data were acquired on an AttuneNxt (ThermoFisher) or on a LSRII (BD Biosciences) and analysed using BD FACS DIVA, ThermoFisher AttuneNext, and FlowJo ${ }^{\mathrm{TM}}$ software (Tree Star Inc.). The gating strategy is shown in Supplementary Fig. 2.

SARS-CoV-2 infection model. The infection experiments were approved by local authorities after review by an ethical commission (TVV 21/20). Eleven weeks old, female K18-hACE2 mice (stock \# 034860, Jackson Laboratory, Bar Harbor, USA) were immunized as described before and infected four weeks after the boost immunization intranasally with $9 \times 10^{3}$ focus-forming units (FFU) of the SARSCoV-2 strain BavPat1 in a total volume of $50 \mu$ under light anaesthesia with inhaled isoflurane. Animals were monitored daily for body weight and clinical score. The following parameters were evaluated in the scoring system: weight loss and body posture ( $0-20$ points), general conditions including the appearance of fur and eye closure ( $0-20$ points), reduced activity and general behaviour changes ( $0-20$ points), and limb paralysis ( $0-20$ points). Mice were euthanized at day 5 after infection or earlier if a cumulative clinical score of 20 or more was reached by a final blood draw under deep narcosis. After euthanasia, the lungs were filled with $800 \mu \mathrm{l}$ PBS and the left lung was tied off. The BAL of the right lung was taken and repeated with two more washes each with $400 \mu$ l. The right lungs as well as the right hemispheres of the brains were homogenized in $1 \mathrm{ml}$ PBS using a gentleMACS Octo Dissociator (Miltenyi Biotec) and viral RNA was isolated from $140 \mu \mathrm{l}$ cleared homogenate or BAL fluid using QIAamp Viral RNA Mini Kit (Qiagen). RT-qPCR reactions were performed using TaqMan ${ }^{\circledR}$ Fast Virus 1-Step Master Mix (ThermoFisher) and $5 \mu \mathrm{l}$ of isolated RNA as a template to detect a 132 bp sequence in the ORF1b/NSP14. Primer and probe sequences were as follows: forward primer, 3'-TGGGGYTTTACRGGTAACCT-5'; reverse primer, 
AACRCGCTTAACAAAGCACTC; probe, 3'-FAM-TAGTTGTGATGCWATCATGACTAG-TAMRA-5'. Synthetic SARS-CoV-2-RNA (Twist Bioscience) was used as a quantitative standard to obtain viral copy numbers ${ }^{90}$. For the detection of infectious virus in BAL and the lung, Vero E6 cells were seeded at $2 \times 10^{4}$ cells/ well in a 96-well plate in $200 \mu \mathrm{l}$ of D10 for confluent monolayer $24 \mathrm{~h}$ prior to infection. After medium change to D10, a two-fold-serial dilution of BALs or lung homogenates were applied to the cells for $3 \mathrm{~h}$. After replacing the supernatant with overlay medium (DMEM with 1\% methyl cellulose, $2 \%$ FBS and $1 \%$ penicillin/ streptomycin), cells were incubated for further $27 \mathrm{~h}$. SARS-CoV-2 infected cells were visualized using SARS-CoV-2 S-protein specific immunochemistry staining with anti-SARS-CoV-2 spike glycoprotein S1 antibody (1:2000; Abcam) and an anti-human-IgG HRP detection antibody (1:1000, Dianova) ${ }^{91}$.

Statistical analyses. Results are shown as mean \pm SEM or as median \pm interquartile range except it is described differently. Statistical analyses were performed with Prism 8.0 (GraphPad Software, Inc.). A $p<0.05$ was considered to be statistically significant. For reasons of clarity, significances are only shown among the vaccine groups.

Reporting summary. Further information on research design is available in the Nature Research Reporting Summary linked to this article.

\section{Data availability}

The raw numbers for charts and graphs are available in the Source Data file whenever possible. The following sequences are publicly accessible: NCBI Reference Sequence NC_045512.2 (https://www.ncbi.nlm.nih.gov/nuccore/1798174254) and GISAID EPI ISL 406862 Germany/BavPat1/2020. This paper does not report original code. Source data are provided with this paper.

Received: 30 July 2021; Accepted: 1 November 2021; Published online: 26 November 2021

\section{References}

1. WHO, W. H. O. COVID-19 Weekly Epidemiological Update, Edition 50. (2021). Available at: https:/www.who.int/publications/m/item/weekly-epidemiologicalupdate-on-covid-19---27-july-2021. (Accessed: 27th July 2021).

2. WHO, W. H. O. COVID-19 vaccine tracker and landscape. (2021). Available at: https://www.who.int/publications/m/item/draft-landscape-of-covid-19candidate-vaccines. (Accessed: 21st July 2021).

3. Baden, L. R. et al. Efficacy and safety of the mRNA-1273 SARS-CoV-2 vaccine. N. Engl. J. Med. 384, 403-416 (2021).

4. Polack, F. P. et al. Safety and efficacy of the BNT162b2 mRNA Covid-19 vaccine. N. Engl. J. Med. 383, 2603-2615 (2020).

5. Voysey, M. et al. Safety and efficacy of the ChAdOx1 $\mathrm{nCoV}-19$ vaccine (AZD1222) against SARS-CoV-2: an interim analysis of four randomised controlled trials in Brazil, South Africa, and the UK. Lancet 397, 99-111 (2021).

6. Logunov, D. Y. et al. Safety and efficacy of an rAd26 and rAd5 vector-based heterologous prime-boost COVID-19 vaccine: an interim analysis of a randomised controlled phase 3 trial in Russia. Lancet 397, 671-681 (2021).

7. Jackson, L. A. et al. An mRNA Vaccine against SARS-CoV-2 - Preliminary Report. N. Engl. J. Med 383, 1920-1931 (2020).

8. Frenck, R. W. et al. Safety, immunogenicity, and efficacy of the BNT162b2 Covid-19 vaccine in adolescents. N. Engl. J. Med. NEJMoa2107456. https:// doi.org/10.1056/NEJMoa2107456 (2021).

9. Sahin, U. et al. BNT162b2 vaccine induces neutralizing antibodies and polyspecific T cells in humans. Nature https://doi.org/10.1038/s41586-021-03653-6 (2021).

10. Logunov, D. Y. et al. Safety and immunogenicity of an $\operatorname{rAd} 26$ and rAd5 vector-based heterologous prime-boost COVID-19 vaccine in two formulations: two open, non-randomised phase $1 / 2$ studies from Russia. Lancet 396, 887-897 (2020).

11. Folegatti, P. M. et al. Safety and immunogenicity of the ChAdOx1 nCoV-19 vaccine against SARS-CoV-2: a preliminary report of a phase 1/2, single-blind, randomised controlled trial. Lancet 396, 467-478 (2020).

12. Kustin, T. et al. Evidence for increased breakthrough rates of SARS-CoV-2 variants of concern in BNT162b2-mRNA-vaccinated individuals. Nat. Med. https://doi.org/10.1038/s41591-021-01413-7 (2021).

13. Abu-Raddad, L. J., Chemaitelly, H. \& Butt, A. A. Effectiveness of the BNT162b2 Covid-19 Vaccine against the B.1.1.7 and B.1.351 Variants. $N$. Engl. J. Med. NEJMc2104974. https://doi.org/10.1056/NEJMc2104974 (2021).

14. Emary, K. R. W. et al. Efficacy of ChAdOx1 $\mathrm{nCoV}-19$ (AZD1222) vaccine against SARS-CoV-2 variant of concern 202012/01 (B.1.1.7): an exploratory analysis of a randomised controlled trial. Lancet 397, 1351-1362 (2021).
15. Madhi, S. A. et al. Efficacy of the ChAdOx1 nCoV-19 Covid-19 Vaccine against the B.1.351 Variant. N. Engl. J. Med. 384, 1885-1898 (2021).

16. Hacisuleyman, E. et al. Vaccine breakthrough infections with SARS-CoV-2 variants. N. Engl. J. Med. 384, 2212-2218 (2021).

17. Farinholt, T. et al. Transmission event of SARS-CoV-2 Delta variant reveals multiple vaccine breakthrough infections. medRxiv Prepr. Serv. Heal. Sci. https://doi.org/10.1101/2021.06.28.21258780 (2021).

18. Brosh-Nissimov, T. et al. BNT162b2 vaccine breakthrough: clinical characteristics of 152 fully vaccinated hospitalized COVID-19 patients in Israel. Clin. Microbiol. Infect. https://doi.org/10.1016/j.cmi.2021.06.036 (2021).

19. Levine-Tiefenbrun, M. et al. Initial report of decreased SARS-CoV-2 viral load after inoculation with the BNT162b2 vaccine. Nat. Med. https://doi.org/ 10.1038/s41591-021-01316-7 (2021).

20. Harris, R. J. et al. Effect of vaccination on household transmission of SARSCoV-2 in England. N. Engl. J. Med. NEJMc2107717. https://doi.org/10.1056/ NEJMc2107717 (2021).

21. Asahi-Ozaki, Y. et al. Secretory IgA antibodies provide cross-protection against infection with different strains of influenza B virus. J. Med. Virol. 74, 328-335 (2004).

22. Renegar, K. B., Small, P. A., Boykins, L. G. \& Wright, P. F. Role of IgA versus $\mathrm{IgG}$ in the control of influenza viral infection in the murine respiratory tract. J. Immunol. 173, 1978-1986 (2004).

23. Okuya, K. et al. Potential role of nonneutralizing IgA antibodies in crossprotective immunity against influenza A viruses of multiple Hemagglutinin Subtypes. J. Virol. 94, e00408-20 (2020).

24. Terauchi, Y. et al. IgA polymerization contributes to efficient virus neutralization on human upper respiratory mucosa after intranasal inactivated influenza vaccine administration. Hum. Vaccin. Immunother. 14, 1351-1361 (2018).

25. Ambrose, C. S., Wu, X., Jones, T. \& Mallory, R. M. The role of nasal IgA in children vaccinated with live attenuated influenza vaccine. Vaccine 30, 6794-6801 (2012)

26. Gould, V. M. W. et al. Nasal IgA provides protection against human influenza challenge in volunteers with low serum influenza antibody titre. Front. Microbiol. 8, 900 (2017).

27. Ainai, A. et al. Human immune responses elicited by an intranasal inactivated H5 influenza vaccine. Microbiol. Immunol. 64, 313-325 (2020).

28. Morokutti, A., Muster, T. \& Ferko, B. Intranasal vaccination with a replication-deficient influenza virus induces heterosubtypic neutralising mucosal IgA antibodies in humans. Vaccine 32, 1897-1900 (2014).

29. Ainai, A. et al. Intranasal vaccination with an inactivated whole influenza virus vaccine induces strong antibody responses in serum and nasal mucus of healthy adults. Hum. Vaccin. Immunother. 9, 1962-1970 (2013).

30. Lapuente, D. et al. IL-1 $\beta$ as mucosal vaccine adjuvant: the specific induction of tissue-resident memory $\mathrm{T}$ cells improves the heterosubtypic immunity against influenza A viruses. Mucosal Immunol. 11, 1265-1278 (2018).

31. See, R. H. et al. Comparative evaluation of two severe acute respiratory syndrome (SARS) vaccine candidates in mice challenged with SARS coronavirus. J. Gen. Virol. 87, 641-650 (2006).

32. Kim, M. H., Kim, H. J. \& Chang, J. Superior immune responses induced by intranasal immunization with recombinant adenovirus-based vaccine expressing full-length Spike protein of Middle East respiratory syndrome coronavirus. PLoS ONE 14, e0220196 (2019).

33. Iborra, S. et al. Optimal generation of tissue-resident but not circulating memory $\mathrm{T}$ cells during viral infection requires crosspriming by DNGR-1+ dendritic cells. Immunity 45, 847-860 (2016).

34. Teijaro, J. R. et al. Cutting edge: tissue-retentive lung memory CD4 T cells mediate optimal protection to respiratory virus infection. J. Immunol. 187, 5510-5514 (2011)

35. Takamura, $\mathrm{S}$. et al. Specific niches for lung-resident memory CD8 $+\mathrm{T}$ cells at the site of tissue regeneration enable CD69-independent maintenance. J. Exp. Med. 213, 3057-3073 (2016).

36. Park, S. L. et al. Local proliferation maintains a stable pool of tissue-resident memory T cells after antiviral recall responses. Nat. Immunol. 19, 183-191 (2018).

37. Schenkel, J. M., Fraser, K. A., Vezys, V. \& Masopust, D. Sensing and alarm function of resident memory CD8(+) T cells. Nat. Immunol. 14, 509-513 (2013).

38. Mackay, L. K. et al. Hobit and Blimp1 instruct a universal transcriptional program of tissue residency in lymphocytes. Sci. (80-.) 352, 459-463 (2016).

39. Wakim, L. M. et al. The molecular signature of tissue resident memory CD8 T cells isolated from the brain. J. Immunol. 189, 3462-3471 (2012).

40. $\mathrm{Wu}, \mathrm{T}$. et al. Lung-resident memory CD8 T cells (TRM) are indispensable for optimal cross-protection against pulmonary virus infection. J. Leukoc. Biol. 95, 215-224 (2014).

41. Zens, K. D., Chen, J. K. \& Farber, D. L. Vaccine-generated lung tissue-resident memory $\mathrm{T}$ cells provide heterosubtypic protection to influenza infection. JCI Insight 1, e85832 (2016).

42. Luangrath, M. A., Schmidt, M. E., Hartwig, S. M. \& Varga, S. M. Tissueresident memory $\mathrm{T}$ cells in the lungs protect against acute respiratory syncytial virus infection. ImmunoHorizons 5, 59-69 (2021). 
43. Darrah, P. A. et al. Prevention of tuberculosis in macaques after intravenous BCG immunization. Nature 577, 95-102 (2020).

44. Sakai, S. et al. Cutting edge: control of mycobacterium tuberculosis infection by a subset of lung parenchyma-homing CD4 T cells. J. Immunol. 192, 2965-2969 (2014).

45. Jozwik, A. et al. RSV-specific airway resident memory CD8+ T cells and differential disease severity after experimental human infection. Nat. Commun. 6, 10224 (2015).

46. Guvenel, A. et al. Epitope-specific airway-resident CD4+ T cell dynamics during experimental human RSV infection. J. Clin. Invest. 130, 523-538 (2019).

47. Hassan, A. O. et al. A single-dose intranasal ChAd vaccine protects upper and lower respiratory tracts against SARS-CoV-2. Cell 183, 169-184.e13 (2020).

48. Hassan, A. O. et al. A single intranasal dose of chimpanzee adenovirusvectored vaccine protects against SARS-CoV-2 infection in rhesus macaques. Cell Rep. Med. 2, 100230 (2021).

49. Bricker, T. L. et al. A single intranasal or intramuscular immunization with chimpanzee adenovirus-vectored SARS-CoV-2 vaccine protects against pneumonia in hamsters. Cell Rep. 109400. https://doi.org/10.1016/ j.celrep.2021.109400 (2021).

50. van Doremalen, N. et al. ChAdOx1 nCoV-19 vaccine prevents SARS-CoV-2 pneumonia in rhesus macaques. Nature 586, 578-582 (2020).

51. van Doremalen, N. et al. Intranasal ChAdOx1 nCoV-19/AZD1222 vaccination reduces shedding of SARS-CoV-2 D614G in rhesus macaques. bioRxiv Prepr. Serv. Biol. https://doi.org/10.1101/2021.01.09.426058 (2021).

52. Altimmune, I. Altimmune Announces Update On AdCOVID ${ }^{\mathrm{TM}}$ Phase 1 Clinical Trial. (2021). Available at: https://ir.altimmune.com/news-releases/ news-release-details/altimmune-announces-update-adcovidtm-phase-1clinical-trial. (Accessed: 21st July 2021)

53. $\mathrm{Wu}, \mathrm{S}$. et al. Safety, tolerability, and immunogenicity of an aerosolised adenovirus type-5 vector-based COVID-19 vaccine (Ad5-nCoV) in adults: preliminary report of an open-label and randomised phase 1 clinical trial. Lancet Infect. Dis. https://doi.org/10.1016/S1473-3099(21)00396-0 (2021).

54. Lapuente, D. et al. Rapid response flow cytometric assay for the detection of antibody responses to SARS-CoV-2. Eur. J. Clin. Microbiol. Infect. Dis. https:// doi.org/10.1007/s10096-020-04072-7 (2020).

55. Anderson, K. G. et al. Cutting edge: intravascular staining redefines lung CD8 T cell responses. J. Immunol. 189, 2702-2706 (2012).

56. Peter, A. S. et al. A pair of non-competing neutralizing human monoclonal antibodies protecting from disease in a SARS-CoV-2 infection model. bioRxiv 2021.04.16.440101. https://doi.org/10.1101/2021.04.16.440101 (2021).

57. Spencer, A. J. et al. Heterologous vaccination regimens with self-amplifying RNA and adenoviral COVID vaccines induce robust immune responses in mice. Nat. Commun. 12, 2893 (2021).

58. He, Q. et al. Heterologous prime-boost: breaking the protective immune response bottleneck of COVID-19 vaccine candidates. Emerg. Microbes Infect. 10, 629-637 (2021)

59. Barros-Martins, J. et al. Immune responses against SARS-CoV-2 variants after heterologous and homologous ChAdOx1 nCoV-19/BNT162b2 vaccination. Nat. Med. https://doi.org/10.1038/s41591-021-01449-9 (2021).

60. Borobia, A. M. et al. Immunogenicity and reactogenicity of BNT162b2 booster in ChAdOx1-S-primed participants (CombiVacS): a multicentre, open-label, randomised, controlled, phase 2 trial. Lancet 398, 121-130 (2021).

61. Normark, J. et al. Heterologous ChAdOx1 nCoV-19 and mRNA-1273 Vaccination. N. Engl. J. Med. NEJMc2110716. https://doi.org/10.1056/ NEJMc2110716 (2021).

62. Tenbusch, M. et al. Heterologous prime-boost vaccination with ChAdOx1 nCoV-19 and BNT162b2. Lancet Infect. Dis. https://doi.org/10.1016/S14733099(21)00420-5 (2021).

63. Lapuente, D., Ruzsics, Z., Thirion, C. \& Tenbusch, M. Evaluation of adenovirus 19 a as a novel vector for mucosal vaccination against influenza A viruses. Vaccine 36, 2712-2720 (2018).

64. Çuburu, N. et al. A Prime-Pull-Amplify vaccination strategy to maximize induction of circulating and genital-resident intraepithelial CD8 + Memory T Cells. J. Immunol. 202, 1250-1264 (2019).

65. Marsh, G. A. et al. ChAdOx1 nCoV-19 (AZD1222) vaccine candidate significantly reduces SARS-CoV-2 shedding in ferrets. npj Vaccines 6, 67 (2021).

66. Bergelson, J. M. et al. Isolation of a common receptor for Coxsackie B viruses and adenoviruses 2 and 5. Science 275, 1320-1323 (1997).

67. Arnberg, N., Kidd, A. H., Edlund, K., Olfat, F. \& Wadell, G. Initial interactions of subgenus D adenoviruses with A549 cellular receptors: Sialic Acid versus alpha v Integrins. J. Virol. 74, 7691-7693 (2000).

68. Cashman, S. M., Morris, D. J. \& Kumar-Singh, R. Adenovirus type 5 pseudotyped with adenovirus type 37 fiber uses sialic acid as a cellular receptor. Virology 324, 129-139 (2004).

69. Wu, E. et al. Membrane cofactor protein is a receptor for adenoviruses associated with epidemic keratoconjunctivitis. J. Virol. 78, 3897-3905 (2004).
70. Li, H. et al. Adenovirus serotype 26 utilizes CD46 as a primary cellular receptor and only transiently activates $\mathrm{T}$ lymphocytes following vaccination of Rhesus Monkeys. J. Virol. 86, 10862-10865 (2012).

71. Hsieh, C.-L. et al. Structure-based design of prefusion-stabilized SARS-CoV-2 spikes. Sci. (80-.) 369, 1501-1505 (2020).

72. Dinnon, K. H. et al. A mouse-adapted model of SARS-CoV-2 to test COVID19 countermeasures. Nature 586, 560-566 (2020).

73. Rathnasinghe, R. et al. The N501Y mutation in SARS-CoV-2 spike leads to morbidity in obese and aged mice and is neutralized by convalescent and postvaccination human sera. medRxiv 2021.01.19.21249592. https://doi.org/ 10.1101/2021.01.19.21249592 (2021)

74. Ma, Y. et al. SARS-CoV-2 infection aggravates chronic comorbidities of cardiovascular diseases and diabetes in mice. Anim. Model. Exp. Med. 4, 2-15 (2021).

75. Lillie, P. J. et al. Preliminary assessment of the efficacy of a T-Cell-based influenza vaccine, MVA-NP+M1, in humans. Clin. Infect. Dis. 55, 19-25 (2012).

76. Pleguezuelos, O. et al. Efficacy of FLU-v, a broad-spectrum influenza vaccine, in a randomized phase IIb human influenza challenge study. npj Vaccines $\mathbf{5}$, $22(2020)$.

77. Khoury, D. S. et al. Neutralizing antibody levels are highly predictive of immune protection from symptomatic SARS-CoV-2 infection. Nat. Med. 27, 1205-1211 (2021).

78. Earle, K. A. et al. Evidence for antibody as a protective correlate for COVID19 vaccines. Vaccine 39, 4423-4428 (2021).

79. Lucas, C. et al. Longitudinal analyses reveal immunological misfiring in severe COVID-19. Nature 584, 463-469 (2020).

80. Van Kampen, K. R. et al. Safety and immunogenicity of adenovirus-vectored nasal and epicutaneous influenza vaccines in humans. Vaccine 23, 1029-1036 (2005).

81. Tasker, S. et al. Safety and immunogenicity of a novel intranasal influenza vaccine (NasoVAX): A phase 2 randomized, controlled trial. Vaccines 9, 224 (2021).

82. Hörnich, B. F. et al. SARS-CoV-2 and SARS-CoV spike-mediated cell-cell fusion differ in their requirements for receptor expression and proteolytic activation. J. Virol. 95, e00002-21 (2021).

83. Ruzsics, Z., Lemnitzer, F. \& Thirion, C. Engineering adenovirus genome by bacterial artificial chromosome (BAC) technology. Methods Mol. Biol. 1089, 143-158 (2014)

84. Vogel, A. B. et al. BNT162b vaccines protect rhesus macaques from SARSCoV-2. Nature 592, 283-289 (2021).

85. Lapuente, D. et al. Innate signalling molecules as genetic adjuvants do not alter the efficacy of a DNA-based influenza A vaccine. PLOS ONE 15, e0231138 (2020).

86. Dispinseri, S. et al. Neutralizing antibody responses to SARS-CoV-2 in symptomatic COVID-19 is persistent and critical for survival. Nat. Commun. 12, 2670 (2021).

87. Hoffmann, M. et al. SARS-CoV-2 variants B.1.351 and P.1 escape from neutralizing antibodies. Cell 184, 2384-2393.e12 (2021).

88. Hoffmann, M. et al. SARS-CoV-2 variant B.1.617 is resistant to bamlanivimab and evades antibodies induced by infection and vaccination. Cell Rep. 109415. https://doi.org/10.1016/j.celrep.2021.109415 (2021).

89. Arora, P. et al. Increased lung cell entry of B.1.617.2 and evasion of antibodies induced by infection and BNT162b2 vaccination. bioRxiv 2021.06.23.449568. https://doi.org/10.1101/2021.06.23.449568 (2021).

90. Groß, R. et al. Detection of SARS-CoV-2 in human breastmilk. Lancet 395, 1757-1758 (2020)

91. Case, J. B., Bailey, A. L., Kim, A. S., Chen, R. E. \& Diamond, M. S. Growth, detection, quantification, and inactivation of SARS-CoV-2. Virology 548, $39-48$ (2020)

\section{Acknowledgements}

We would like to thank Drew Hannaman (Ichor Medical Systems, Inc.) for providing the TriGrid electrode array for DNA electroporation, Anne-Kathrin Donner for excellent technical assistance, and the group of Dr. Jasmin Fertey (Fraunhofer IZI, Leipzig, Germany) for providing viral stocks for mouse infections. Moreover, we kindly thank Thomas Schumacher (Virion/Serion GmbH, Würzburg, Germany) and Diarect GmbH (Freiburg, Germany) for providing the Spike peptides. The ELISPOT Analyzer was obtained with financial support from Fondation Dormeur, Vaduz. This work was supported within the FOR-COVID project funded by the Bavarian State ministry for Science and the Arts (to M.T. and K.Ü.). Further support was provided by B-FAST, a BMBFfunded project of the Netzwerk Universitätsmedizin (NaFoUniMedCovid19; FKZ: 01KX2021; to K.Ü.) and funds from the Deutsche Forschungsgemeinschaft (DFG) through the research training group RTG 2504 (project number: 401821119, to A.V.A, M.T., K.Ü.). S.P. acknowledges funding by BMBF (01KI2006D, 01KI20328A, 01 KI20396, 01KX2021), the Ministry for Science and Culture of Lower Saxony (14-76103-184, MWK HZI COVID-19) DFG (PO 716/11-1, PO 716/14-1). 


\section{Author contributions}

D.L., T.G., K.Ü., and M.T. conceived and designed the study. D.L., J.F., J.W., A.V.A., V.E., N.U., L.I., A.S., F.O., A.S.P., P.I., and K.F. collected the data. D.L., J.F., J.W., A.V.A., V.E., N.U., L.I., T.G., and M.T. performed the analysis. S.M.-S., A.C., A.E., M.H., S.P., C.P., T.W., and C.T. contributed critical reagents. D.L. and M.T. drafted the manuscript, which was then critically reviewed and approved by all co-authors.

\section{Funding}

Open Access funding enabled and organized by Projekt DEAL.

\section{Competing interests}

C.T. is founder and shareholder of SIRION Biotech $\mathrm{GmbH}$. The other authors declare no competing interests.

\section{Additional information}

Supplementary information The online version contains supplementary material available at https://doi.org/10.1038/s41467-021-27063-4.

Correspondence and requests for materials should be addressed to Dennis Lapuente or Matthias Tenbusch.
Reprints and permission information is available at http://www.nature.com/reprints

Publisher's note Springer Nature remains neutral with regard to jurisdictional claims in published maps and institutional affiliations.Peer review information Nature Communications thanks David Lo and the other, anonymous, reviewer(s) for their contribution to the peer review of this work. Peer reviewer reports are available.

cc) (i) Open Access This article is licensed under a Creative Commons Attribution 4.0 International License, which permits use, sharing, adaptation, distribution and reproduction in any medium or format, as long as you give appropriate credit to the original author(s) and the source, provide a link to the Creative Commons license, and indicate if changes were made. The images or other third party material in this article are included in the article's Creative Commons license, unless indicated otherwise in a credit line to the material. If material is not included in the article's Creative Commons license and your intended use is not permitted by statutory regulation or exceeds the permitted use, you will need to obtain permission directly from the copyright holder. To view a copy of this license, visit http://creativecommons.org/ licenses/by/4.0/.

(C) The Author(s) 2021 